University of Nebraska - Lincoln

DigitalCommons@University of Nebraska - Lincoln

2012

\title{
Developing slow-release persulfate candles to treat BTEX contaminated groundwater
}

Ann Kambhu

University of Nebraska-Lincoln, annkambhu@gmail.com

Steve D. Comfort

University of Nebraska-Lincoln, scomfort1@unl.edu

Chanat Chokejaroenrat

University of Nebraska-Lincoln, chanatunl@gmail.com

Chainarong Sakulthaew

University of Nebraska-Lincoln, chainarong@huskers.unl.edu

Follow this and additional works at: https://digitalcommons.unl.edu/natrespapers

Part of the Natural Resources and Conservation Commons

Kambhu, Ann; Comfort, Steve D.; Chokejaroenrat, Chanat; and Sakulthaew, Chainarong, "Developing slowrelease persulfate candles to treat BTEX contaminated groundwater" (2012). Papers in Natural Resources. 329.

https://digitalcommons.unl.edu/natrespapers/329

This Article is brought to you for free and open access by the Natural Resources, School of at DigitalCommons@University of Nebraska - Lincoln. It has been accepted for inclusion in Papers in Natural Resources by an authorized administrator of DigitalCommons@University of Nebraska - Lincoln. 


\title{
Developing slow-release persulfate candles to treat BTEX contaminated groundwater
}

\author{
Ann Kambhu, ${ }^{1}$ Steve Comfort ${ }^{2}$ Chanat Chokejaroenrat, ${ }^{1}$ Chainarong Sakulthaew ${ }^{2,3}$ \\ 1. Department of Civil Engineering, University of Nebraska-Lincoln, Lincoln, NE 68583-0531, USA \\ 2. School of Natural Resources, University of Nebraska-Lincoln, Lincoln, NE 68583-0915, USA \\ 3. Department of Veterinary Technology, Kasetsart University, Bangkok 10900, Thailand \\ Corresponding author - S. Comfort, tel 402 4721502, fax 402 472-7904, email scomfort1@unl.edu \\ Email addresses - annkambhu@gmail.com (A. Kambhu), chanatunl@gmail.com (C. Chokejaroenrat), \\ chainarong@huskers.unl.edu (C. Sakulthaew)
}

\begin{abstract}
The development of slow-release chemical oxidants for sub-surface remediation is a relatively new technology. Our objective was to develop slow-release persulfate-paraffin candles to treat BTEX-contaminated groundwater. Laboratory-scale candles were prepared by heating and mixing $\mathrm{Na}_{2} \mathrm{~S}_{2} \mathrm{O}_{8}$ with paraffin in a 2.25 to 1 ratio $(\mathrm{w} / \mathrm{w})$, and then pouring the heated mixture into circular molds that were $2.38 \mathrm{~cm}$ long and either 0.71 or $1.27 \mathrm{~cm}$ in diameter. Activator candles were prepared with $\mathrm{FeSO}_{4}$ or zerovalent iron (ZVI) and wax. By treating benzoic acid and BTEX compounds with slow-release persulfate and ZVI candles, we observed rapid transformation of all contaminants. By using ${ }^{14} \mathrm{C}$-labeled benzoic acid and benzene, we also confirmed mineralization (conversion to CO2) upon exposure to the candles. As the candles aged and were repeatedly exposed to fresh solutions, contaminant transformation rates slowed and removal rates became more linear (zero-order); this change in transformation kinetics mimicked the observed dissolution rates of the candles. By stacking persulfate and ZVI candles on top of each other in a saturated sand tank $(14 \times 14 \times 2.5 \mathrm{~cm})$ and spatially sampling around the candles with time, the dissolution patterns of the candles and zone of influence were determined. Results showed that as the candles dissolved and persulfate and iron diffused out into the sand matrix, benzoic acid or benzene concentrations $\left(C_{o}=1 \mathrm{mM}\right)$ decreased by $>90 \%$ within $7 \mathrm{~d}$. These results support the use of slow-release persulfate and ZVI candles as a means of treating BTEX compounds in contaminated groundwater.
\end{abstract}

Keywords: persulfate, benzene, toluene, ethyl benzene, xylene

\section{Introduction}

One of the biggest threats to groundwater quality in the United States is leaking petroleum from underground storage tanks (UST). Currently there are approximately 597,000 federally-regulated active UST at $\sim 215,000$ sites in the US (USEPA, 2011). When petroleum tanks leak, they contaminate soil and groundwater with a number of soluble and hazardous compounds, most notably, BTEX compounds.

Over the last $25 \mathrm{yr}$, considerable progress has been achieved in developing various treatments for remediating soils and groundwater contaminated with petroleum prod- ucts. Despite these advances, new technologies are still being sought to deal with BTEX compounds located in difficult formations, such as low permeable aquifers. In situ chemical oxidation (ISCO) is the relatively mature practice of injecting liquid oxidants into groundwater for the treatment of contaminants such as BTEX and chlorinated solvents. Specific oxidants commonly used with ISCO include sodium and potassium permanganate, hydrogen peroxide (Fenton's reagent), ozone, and persulfate. While permanganate is the most frequently used oxidant with ISCO applications (Krembs et al., 2011), it is not effective in removing benzene, the regulatory driver for remediating most UST sites. 
Persulfate (peroxydisulfate) is the newest chemical oxidant used for ISCO, having only come into consideration over the last few years. Persulfate has a standard reduction potential of $2.01 \mathrm{~V}$ (Latimer, 1952; House, 1962), which is higher than those of hydrogen peroxide $\left(E^{\circ}=1.77 \mathrm{~V}\right)$ and permanganate $\left(E^{\circ}=1.67 \mathrm{~V}\right)$ but lower than hydroxyl radicals $\left(E^{\circ}=2.7 \mathrm{~V}\right)$ or ozone $\left(E^{\circ}=2.07 \mathrm{~V}\right)$ (Latimer, 1952). Persulfate is known to react directly with some organic compounds but can be kinetically slow in transforming some contaminants (ITRC, 2005; Osgerby, 2006; Petri et al., 2011). In addition to direct accepting electrons, persulfate can be purposely induced to form sulfate radicals $\left(\mathrm{SO}_{4}^{-}\right)$. The sulfate radical has a redox potential of $2.6 \mathrm{~V}(\mathrm{~Eb}-$ erson, 1987), which gives it more potential to degrade a larger variety of contaminants than the parent persulfate molecule $\left(E^{\circ}=2.01 \mathrm{~V}\right)$. Common activators used to produce persulfate radical formation include heat, $\mathrm{Fe}(\mathrm{II}), \mathrm{H}_{2} \mathrm{O}_{2}$ and alkaline $\mathrm{pH}$.

Several researchers have reported positive results in treating BTEX compounds with persulfate in contaminated soil and water (Huang et al., 2005; Crimi and Taylor, 2007; Killian et al., 2007; Liang et al., 2008; Achugasim et al., 2011; Lemaire et al., 2011). Some examples include Huang et al. (2005), who used heat-activated persulfate to degrade 59 volatile organic compounds, which included BTEX, as well as some other benzene derivatives. Lemaire et al. (2011) degraded a BTEX mixture consisting mainly of xylenes with unactivated and Fe(II)activated persulfate while Liang et al. (2008) compared Fe(II) chelating agents and showed that citric acid was most suitable in the iron activated persulfate system for treating benzene.

A challenge to successfully implementing ISCO in aquifers is when the contaminants of interest are present in low permeable zones. Most ISCO treatments to date have involved injecting liquid oxidants. A common problem with any chemical injection however, is that some sites may have finer textured soils that do not readily accept liquid injections. When this occurs, the chemical oxidant can be observed coming back out of the injection borehole because it offers the path of least resistance. Difficulty in addressing contamination in low permeable soils may be alleviated to some degree by taking a passive approach where a slow-release oxidant is inserted into the formation and allowed to dissolve and intercept the contaminant over many years.

While the development and testing of slow-release permanganate has been investigated for a number of years (Ross et al., 2005; Lee and Schwartz, 2007a; Swearingen and Swearingen, 2008), the use of slow-release persulfate for BTEX treatment has only recently been reported. Liang et al. (2011) created a slow-release persulfate cement cube $(4 \times 6 \times 7 \mathrm{~cm})$ that consisted of persulfate (sodium or potassium), cement, sand, and water. Liang et al. (2011) evaluated these persulfate cubes in column experiments to quantify their efficacy in removing benzene and MTBE. When activated with $\mathrm{Fe}(\mathrm{II})$, the persulfate cube $(270 \mathrm{~g})$ was able to oxidize $95-99 \%$ of the benzene $\left(0.2 \mathrm{mg} \mathrm{L}^{-1}\right)$ and $86-92 \% \operatorname{MTBE}\left(0.3 \mathrm{mg} \mathrm{L}^{-1}\right)$ during miscible displacement for several pore volumes. These results support using slow-release persulfate as a means of treating petroleum contaminated groundwater.

Although several researchers have suggested creating in situ oxidant barriers as a means of halting the migration of contaminants (e.g., [Ross et al., 2005; Lee and Schwartz, 2007a; Lee et al., 2009; Liang et al., 2011), field-scale testing of slowrelease oxidants is only beginning. Christenson (2011) reported one of the first field trials where a slow-release oxidant was inserted into a trichloroethene (TCE)-contaminated aquifer at an abandoned landfill. In this study, multiple $91 \mathrm{~cm}(3 \mathrm{ft})$ long permanganate candles (paraffin wax - permanganate) were manufactured and inserted into the aquifer by either direct push or encased in carriers and lowered into permanent wells to create an ISCO barrier. Initial results showed a 64-
82\% reduction in TCE within the first year (Christenson, 2011). To expand on the research reported by Christenson (2011), our objective was to develop similar slow-release persulfate-paraffin candles that could potentially be used to treat BTEX-contaminated groundwater. We accomplish this by conducting a series of laboratory experiments that combined and tested the efficacy of various persulfate and activator candles. A prototype of a combined persulfate-zerovalent iron (ZVI) candle for field-scale use is also presented.

\section{Materials and methods}

\subsection{Candle preparation}

Initial attempts to produce slow-release persulfate candles began by manufacturing a single candle containing a mixture of persulfate, activator and chelator. Specifically, we blended paraffin, persulfate, $\mathrm{Fe}(\mathrm{II})\left(\mathrm{FeSO}_{4} \cdot 7 \mathrm{H}_{2} \mathrm{O}\right)$ as an activator, and citric acid as an iron chelator. Because these mixed composition candles (herein after referred to as "mixed candles") did not provide consistent performance and were short-lived (explained below), individual persulfate and activator candles were made. Details of procedures used to manufacture mixed candles is presented in Supplementary Material (SM, Sec. 1.0).

\subsubsection{Persulfate candles}

A 6-quart electric skillet was used to create a constant temperature water bath for making slow-release persulfate candles. Persulfate candles were prepared in batches as follows: water was preheated to $70 \pm 5^{\circ} \mathrm{C}$ and used to melt $10 \mathrm{~g}$ of straight solid paraffin wax (Peak Candle Supply-IGI 1343A) contained in a 100-mL glass beaker. Once melted, $22.5 \mathrm{~g}$ of sodium persulfate $\left(\mathrm{Na}_{2} \mathrm{~S}_{2} \mathrm{O}_{8}\right.$, Reagent grade $\geq 98 \%$, Sigma Aldrich, St. Louis, MO) was added to the wax. The mixture was blended by hand and then poured into cylindrical molds to create two sizes of candles (Small dia: $0.71 \mathrm{~cm}$; Large dia: $1.27 \mathrm{~cm}$; both $2.38 \mathrm{~cm}$ in length). After letting the candles set in their molds for 2 to $3 \mathrm{~min}$, the candle were pushed out with a metal dowel and allowed to cool overnight before use. Final candle weights were $1.5 \mathrm{~g}$ for the small diameter candles and $4.8 \mathrm{~g}$ for the large diameter candles.

\subsubsection{Activator candles}

A slow-release $\mathrm{Fe}(\mathrm{II})$ candle $\left(\mathrm{FeSO}_{4} \cdot 7 \mathrm{H}_{2} \mathrm{O}\right)$ was made in the same manner as the persulfate candles, with ferrous sulfate (12 g) being added in place of sodium persulfate. As an alternative to $\mathrm{Fe}(\mathrm{II})$ candles, slow-release ZVI candles were also prepared by mixing $10 \mathrm{~g}$ of paraffin wax with $47 \mathrm{~g}$ ZVI (44 $\mu \mathrm{m}$ mesh, Aldrich Chemical, Milwaukee, WI). Initial ZVI candles were made with Aldrich iron powder but later experiments compared and investigated different cast iron sizes (see Section 2.3.3) and as a result, a second set of ZVI candles was prepared using Peerless 50D Type USMD cast iron. These ZVI candles were prepared in a similar manner but because of the coarser grain size, one-half as much ZVI (23.5 g) was used in order to maintain the same consistency of the melted mixture before pouring into the molds.

\subsection{Chemical release rates from candles}

To quantify persulfate release rates, laboratory experiments were conducted with both size candles $(0.71$ and $1.27 \mathrm{~cm}$ dia). The $0.71 \mathrm{~cm}$ candles were placed in 125-mL Erlenmeyer flask filled with $100 \mathrm{~mL}$ distilled water; the $1.27-\mathrm{cm}$ dia candles were placed in $250-\mathrm{mL}$ flasks containing $200 \mathrm{~mL}$ water. Sample temperature was maintained at room temperature. Once the candles were immersed in water, the solution was 
sub-sampled via pipette every $30 \mathrm{~min}$ for the first $4 \mathrm{~h}$, and approximately every 2-3 d until the remainder of the experiment. Immediately prior to each sampling, the solutions were gently swirled to mix. All samples were analyzed colormetrically with iodide on a Hach DR 2800 Visual Spectrum Spectrophotometer at $450 \mathrm{~nm}$. When needed, samples were diluted with $\mathrm{H}_{2} \mathrm{O}$ so that measured concentrations fell within the linear absorbance range $\left(<150 \mathrm{mg} \mathrm{L}^{-1}\right)$.

To characterize the release of persulfate from the slow-release sodium persulfate candles, we determined cumulative persulfate released with time. Mass of released persulfate was calculated from the concentration of persulfate in solution $\left(\mathrm{mg} \mathrm{L}^{-1}\right)$ and volume of the solution (L).

The ability of the ZVI candles to release iron was also quantified. A ZVI candle was placed in a plastic bottle with a persulfate candle and $\mathrm{H}_{2} \mathrm{O}$. At selected times, aliquots were withdrawn and total iron was measured colormetrically with 1,10-phenanthroline at a wavelength of $510 \mathrm{~nm}$ (Olson, 1965) using a HACH Spectrophotometer DR2800 (HACH, Loveland, $\mathrm{CO})$. We included persulfate candles in the iron release experiments because they greatly increased the dissolution rates of the iron candles and therefore, results were more representative of the two candle system (persulfate and activator).

\subsection{Kinetic experiments}

Kinetic degradation experiments were conducted with benzoic acid, benzene and BTEX mixture and the various candles developed. Control experiments, which verified that persulfate, benzoic acid and benzene were not reacting or adsorbing to the paraffin wax matrix, are presented in Supplementary Material (in Figs. SM-1 to SM-3). Methods used to compare the kinetics of contaminant destruction from various iron sources and the pairing of persulfate candles with different length ZVI candles are presented in Supplementary Material (in SM Sec. 1.3-1.4). Control experiments showing the efficacy of thiosulfate to quench persulfate and stop the further transformation of benzoic acid and benzene are presented in Supplementary Material (in Figs. SM-4 and SM-5).

\subsubsection{Benzoic acid}

Quantifying the ability of the persulfate candles to transform contaminants began with batch experiments using benzoic acid. Benzoic acid $\left(\mathrm{C}_{7} \mathrm{H}_{6} \mathrm{O}_{2}\right.$, ASC Reagent grade, SigmaAldrich, St. Louis, MO) was used as a surrogate for BTEX because it is less volatile and negated the need for a zero headspace experimental unit (used in later experiments). Benzoic acid experiments were conducted in 250-mL Erlenmeyer flasks under batch conditions. To each flask, $200 \mathrm{~mL}$ of benzoic acid solution $\left(C_{0}=0.1 \mathrm{mM}\right)$ was added to the flask with a slow release persulfate candle and a ZVI candle (or a mixed candle) and agitated on an orbital shaker. In some experiments, solutions were spiked with $1 \mathrm{~mL}$ of ${ }^{14} \mathrm{C}$-benzoic acid (ring- ${ }^{14} \mathrm{C}$, Moravek Biochemicals, Brea, CA, specific activity: $60 \mathrm{mCi} \mathrm{mmol}^{-1}$ ) so that mineralization rates (conversion to ${ }^{14} \mathrm{CO}_{2}$ ) could also be quantified. Temporal changes in concentrations were obtained by removing $1 \mathrm{~mL}$ samples at selected times and quenching the reaction by mixing with $0.17 \mathrm{~g}$ of sodium thiosulfate (ReagentPlus, 99\%, Sigma-Aldrich, St. Louis, MO) in a 1.5-mL microcentrifuge tube and centrifuging for $15 \mathrm{~min}$ at $14,000 \mathrm{~g}$. The supernatant was then transferred to a glass vial and analyzed with HPLC. Temporal changes in radioactivity were determined by mixing $1 \mathrm{~mL}$ samples with $0.5 \mathrm{~mL}$ of $2 \mathrm{~N} \mathrm{H}_{2} \mathrm{SO}_{4}$, to release $\mathrm{CO}_{2}$ and then mixed with $5 \mathrm{~mL}$ of scintillation cocktail.

\subsubsection{Repeated exposure experiments}

Chemical dissolution rates from slow-release oxidants can be characterized as an initial flush followed by a slower and sustained release (Kang et al., 2004; Lee and Schwartz, 2007a;
Christenson, 2011). To quantify the longevity of the slow-release candles to continually transform benzoic acid (or BTEX compounds), a series of experiments were performed where fresh solutions of contaminants were added to the same candle in repetitive batches. This was accomplished by mixing the contaminant solution with the slow release candles (mixed, persulfate $+\mathrm{ZVI}$ ) and temporally removing samples to quantify degradation rates (either every 3 or $24 \mathrm{~h}$, depending on candle diameter size). Once the contaminant was transformed, the treated solution was discarded and fresh solution added so that temporal changes in contaminant concentration could be measured again. This process of adding fresh solution (benzoic acid or BTEX compounds) to the same candle or candles was repeated multiple times.

\subsection{3. ${ }^{14}$ C-Benzene and BTEX}

The ability of the persulfate and ZVI candles to degrade BTEX compounds were performed in 100-mL gas tight syringes equipped with septum valves (SGE, Austin, TX) in a manner similar to that described by Huang et al. (2002). In these experiments, small diameter persulfate and ZVI candles, and a magnetic stirring bar were placed inside the syringe barrel before filling with $100 \mathrm{~mL}$ of benzene or a BTEX mixture (0.1-1.0 mM). Once filled, any trapped air inside the syringe was pushed out and the syringe was placed on a magnetic stirrer (Barnstead, Thermolyne Cimarec 2 Stirrer, S46725, Dubuque, IA).

Benzene solutions were prepared by mixing deionized $\mathrm{H}_{2} \mathrm{O}$ (that was sonicated prior to use to remove dissolved gases) and benzene stock solution to the desired concentration. For some experiments, ${ }^{14} \mathrm{C}$-benzene (Moravek Biochemicals, Brea, CA specific activity: $100 \mathrm{mCi} \mathrm{mmol}^{-1}$ ) was spiked into the benzene solution so that mineralization could also be quantified.

At selected times, $0.5 \mathrm{~mL}$ aliquots were withdrawn from the $100-\mathrm{mL}$ syringe using a $1-\mathrm{mL}$ gas tight syringe that was already prefilled with $0.1 \mathrm{~mL} 2 \mathrm{M}$ sodium thiosulfate with zero headspace. Sodium thiosulfate was used to quench the persulfate and stop the reaction. The solution was then transferred to a HPLC vial that was prefilled with $1.2 \mathrm{~mL}$ acetonitrile (HPLC grade, Gibbstown, NJ) to prevent volatilization. BTEX compounds were then analyzed with HPLC. Experiments were repeated with a mixture of BTEX compounds $\left(C_{0}=0.10 \mathrm{mM}\right.$ benzene; $0.08 \mathrm{mM}$ toluene, $0.07 \mathrm{mM}$ ethylbenzene, and $0.07 \mathrm{mM}$ of all three xylenes: o-, p- and m-xylene) using freshly prepared persulfate and ZVI candles and candles that were aged for $48 \mathrm{~h}$.

\subsection{Tank experiments}

A $14 \times 14 \times 2.5 \mathrm{~cm} \mathrm{2-D} \mathrm{tank} \mathrm{was} \mathrm{used} \mathrm{to} \mathrm{determine} \mathrm{the} \mathrm{ra-}$ dius of influence of the persulfate and ZVI candles. The 2D tank was equipped with a glass front for viewing and a solid back that contain 30 septa-sealed sampling ports, spaced $2 \mathrm{~cm}$ apart, and arranged in a 5 by 6 array. In the center of the tank, we placed a slotted PVC pipe (2 cm dia) to simulate a well (see Figure SM-6). In that well, we placed large diameter persulfate and ZVI candles. Specifically, a two to one persulfate to ZVI candle ratio was used by stacking three persulfate $(2.38 \mathrm{~cm}$ length) and three ZVI $(1.19 \mathrm{~cm})$ candles on top of each other, such that the persulfate candles were separated by a ZVI candle.

To visualize dissolution patterns and zone of influence, we packed the tank with silica sand (297-420 $\mu \mathrm{m}$ mesh size) and flooded the tank with methylene blue dye $\left(\sim 0.2 \mathrm{~g} \mathrm{~L}^{-1}\right)$, which we found turned colorless upon exposure to persulfate and ZVI candles. Control tests verified the dye was neutralized (i.e., turned colorless) when exposed to persulfate and ZVI candles but not persulfate or ZVI alone. In this experiment, photographs of the $2 \mathrm{D}$ tank were taken every day to visually 


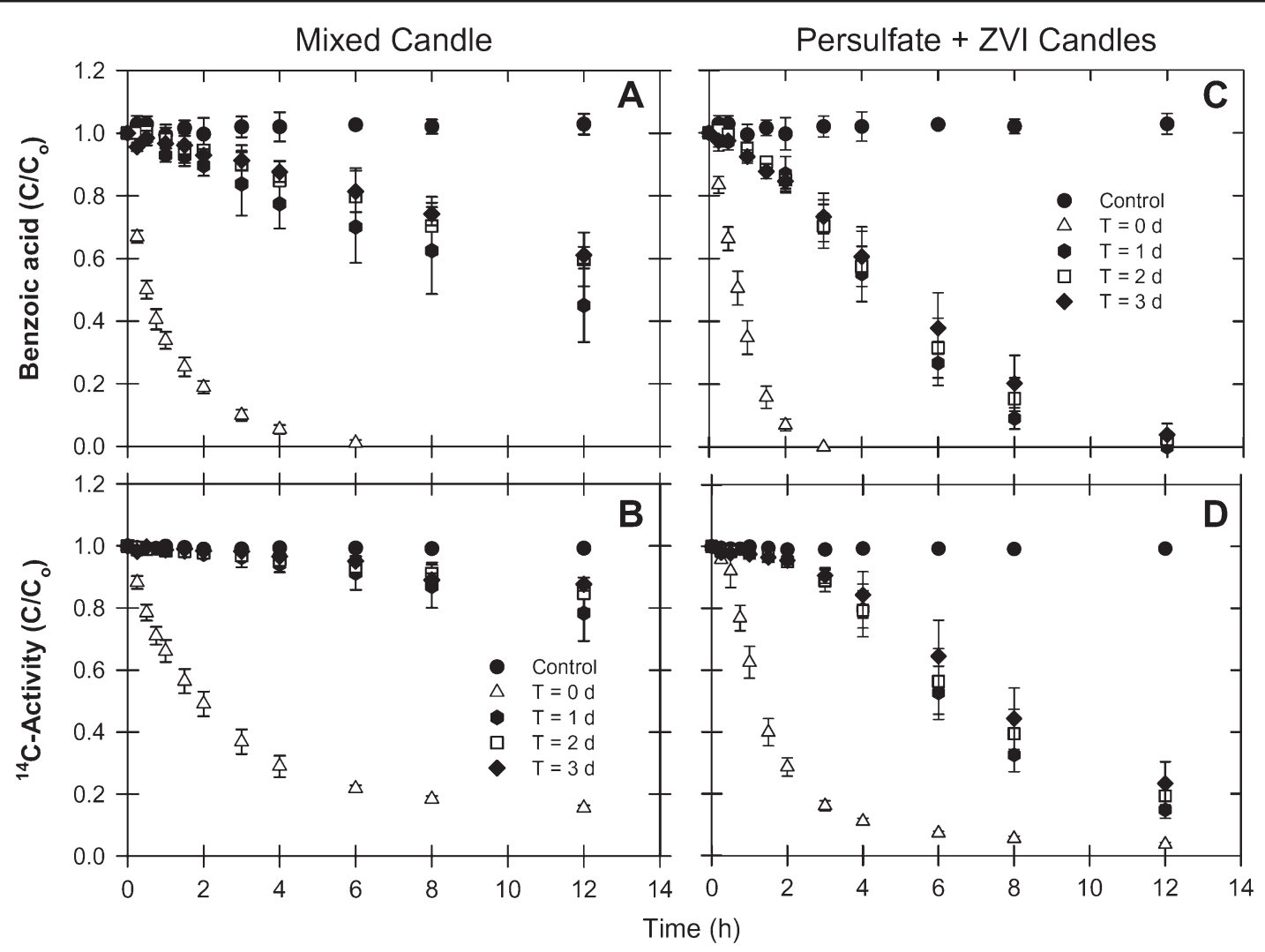

Figure 1. (A) Temporal changes in benzoic acid concentrations $\left(C_{o}=0.1 \mathrm{mM}\right)$ and ${ }^{14} \mathrm{C}$-activity (B) following treatment with mixed candle (persulfate, $\mathrm{Fe}(\mathrm{II})$, and citrate). (C) Temporal changes in benzoic acid concentrations $\left(\mathrm{C}_{\mathrm{o}}=0.1 \mathrm{mM}\right)$ and ${ }^{14} \mathrm{C}$-activity $(\mathrm{D})$ following treatment with persulfate + ZVI candles. Bars on symbols represent sample standard deviations.

record the dissolution and diffusion patterns of the chemicals released from the candle.

A second and third set of experiments packed the tank with silica sand and flooded the tank with either $1 \mathrm{mM}$ benzoic acid or benzene in separate experiments. Samples were removed from the sampling grid after 2 and $7 \mathrm{~d}$ to determine the radius of influence. Contour plots of benzoic acid and benzene concentrations were plotted with SigmaPlot scientific analysis and graphing software.

\subsection{Chemical analysis}

Details of analytical procedures used to quantify benzoic acid, BTEX compounds and ${ }^{14} \mathrm{C}$-activity are presented in Supplementary Material (SM Sec. 1.1).

\section{Results and discussion}

\subsection{Longevity of mixed candle}

Using the mixed candle (persulfate + Fe(II) + citric acid) to transform $0.1 \mathrm{mM}$ benzoic acid showed that the initial reaction rate was very fast, with $100 \%$ removal observed within $6 \mathrm{~h}$ (Figure 1). However, when that same mixed candle was placed in fresh benzoic acid in subsequent batches, results showed that the longevity of the mixed candle was limited. By the time the candle had been immersed in solution for $2 \mathrm{~d}$ (third cycle, $t=2 \mathrm{~d}$ ), only $\sim 40 \%$ of benzoic acid was transformed within the next $12 \mathrm{~h}$ (Figure 1a). The longevity of the mixed candle to mineralize ${ }^{14} \mathrm{C}$-labeled benzoic acid was even shorter, with a significant decline in performance observed after the first cycle (Figure 1b). While Christenson (2011) showed that slow-release permanganate candles exhibit a rapid re- lease of permanganate, followed by a slower release rate, the inability of our mixed persulfate candle to continually transform benzoic acid cannot solely be explained by the physical diffusion constraints of the paraffin matrix. Other reasons for this reduced efficacy include compatibility issues between the persulfate, $\mathrm{Fe}(\mathrm{II})$ and citric acid, either during initial blending or afterwards while in the candle matrix. It was noted that the mixed candles appeared to pick up moisture upon standing (days) and change colors from greenish-yellow to white. Another problem with the mixed candle occurred during blending where we found that the ferrous sulfate was very sensitive to temperature and that overheating by just one or two degrees caused the candles to turn from green to yellow, indicating ferrous iron oxidation. When we separated the mixed candle components into individual candles of persulfate, $\mathrm{FeSO}_{4}$ and citric acid, we observed that the citric acid was much more readily released from the paraffin matrix than persulfate or $\mathrm{FeSO}_{4}$. For these reasons, candle experiments shifted to using ZVI as an activator without citric acid.

\subsection{Treatment of benzoic acid with persulfate and ZVI candles}

Treating benzoic acid with separate persulfate and ZVI candles showed that the initial reaction rate between the candles and benzoic acid were again fast with complete removal occurring within $3 \mathrm{~h}$ (Figure 1c). Adding fresh benzoic acid to the candles every $24 \mathrm{~h}$ revealed that removal rates did not taper off as quickly as those observed with the mixed candle (Figure 1a vs. c). For example, after 3 cycles of exposure $(t=2 \mathrm{~d})$, the persulfate + ZVI candles were still able to transform $\sim 100 \%$ of the benzoic acid within $12 \mathrm{~h}$ (Figure 1c). The temporal changes in reaction kinetics upon repeated exposure can be explained by examining the release rates of persulfate 

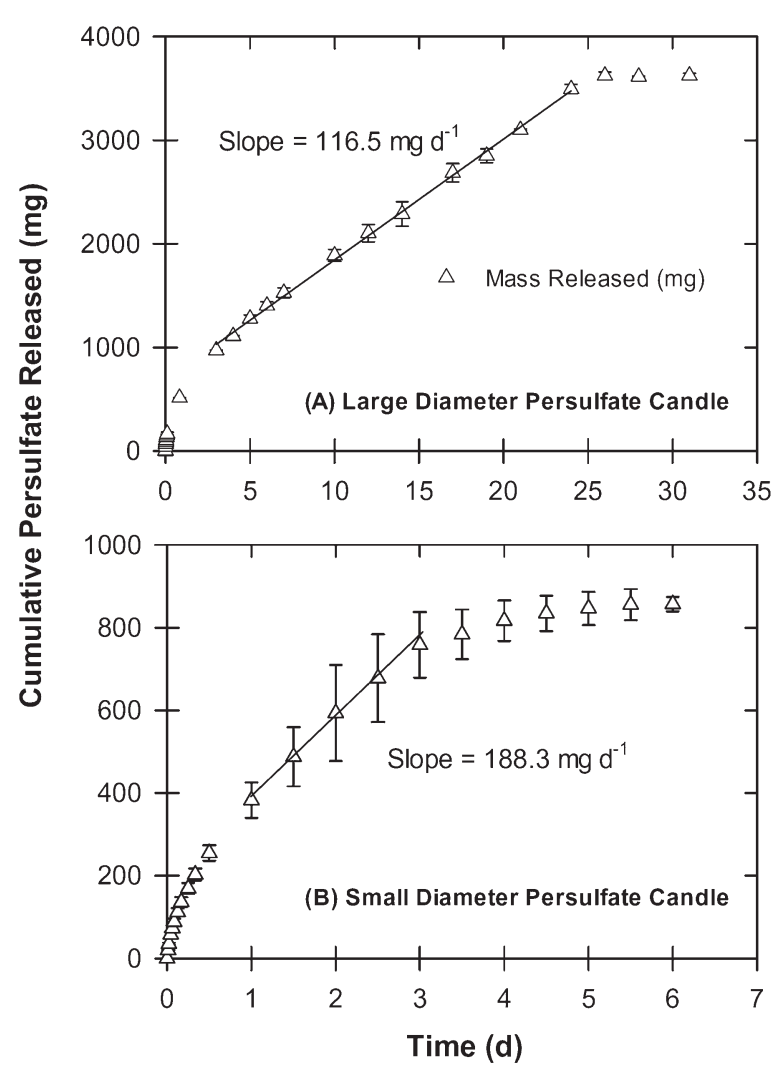

Figure 2. Chemical release characteristics from large and small diameter persulfate candles. Note differences in time axes between plots A and B.

and iron from the candles (see Section 3.3). Tracking changes in ${ }^{14} \mathrm{C}$-concentrations confirmed mineralization was also occurring with the persulfate and ZVI candles (Figure 1d) and this two candle system performed significantly better than the mixed candle (Figure 1b).

\subsection{Persulfate release rates}

Release rates were measured from the large and small diameter persulfate candles with results confirming that candles dimensions influenced persulfate release. As observed with other slow-release oxidants (Kang et al., 2004; Lee and Schwartz, 2007a; Lee and Schwartz, 2007b), large fluxes of persulfate were initially observed from the small and large diameter candles as the persulfate located on the surface of the candle dissolved into solution. This initial flux occurred within the first day for the small diameter candle and within the first 3-4 d for the large diameter candle. After this initial release (Figure 2), the large diameter candles were much more consistent in releasing persulfate. After $4 \mathrm{~d}$ of being immersed in $\mathrm{H}_{2} \mathrm{O}$, the release rate was linear at $117 \mathrm{mg} \mathrm{d}^{-1}$. By $25 \mathrm{~d}$, the large diameter candle was spent and all of the persulfate $(\sim 100 \%)$ had been released. By contrast, the small candle had a slightly larger release rate $\left(189 \mathrm{mg} \mathrm{d}^{-1}\right)$ but began to show signs of slowing down or releasing less persulfate by $3 \mathrm{~d}$; by $6 \mathrm{~d} \sim 82 \%$ of the persulfate had been released. The observed change in dissolution patterns can be explained by the dissolution front retreating back into the paraffin matrix and the diffusion paths increasing. These changes in releases patterns were also manifested in the removal kinetics observed for benzoic acid (exponential decline vs. linear, Figure 1c).

\subsection{Comparison of iron sources as activators}

Batch experiments confirmed that within the timeframe of the experiments, benzoic acid was not reactive to persulfate
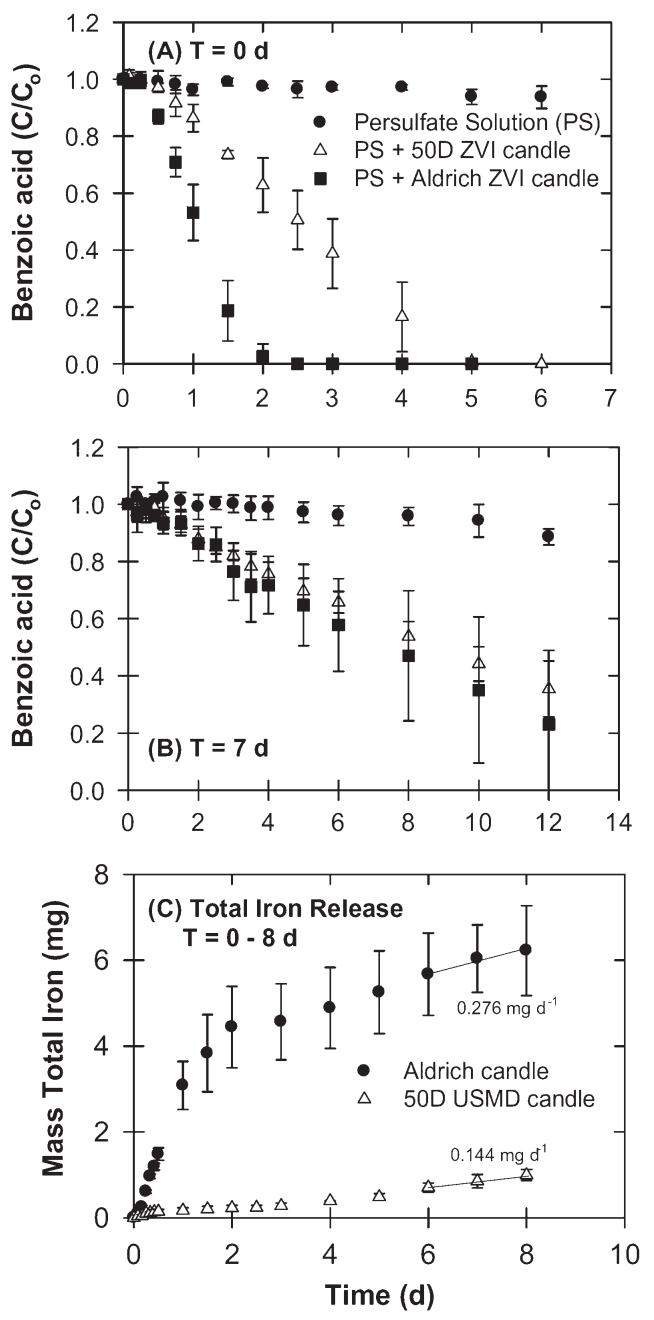

Figure 3. Changes in benzoic acid concentration $\left(C_{o}=0.10 \mathrm{mM}\right)$ when treated with persulfate solution $(10 \mathrm{mM})$ and two types of ZVI candles. (A) Results using fresh candles $(T=0 \mathrm{~h})$. (B) Results using aged ZVI candles $(T=48 \mathrm{~h})$. (C) Mass of iron released from ZVI candles. Note that Figures A, B, and C have different time scales.

alone and activation to sulfate radicals was required to observed transformation (Figure SM-7). Liang and Lai (2008) and Liang and Guo (2010) showed that ZVI was an effective activator for persulfate in treating TCE and naphthalene. Although the composition of analytical reagents is generally uniform between vendors, the chemical makeup of various cast irons can vary widely due to differences in manufacturing practices and feed stocks. By testing various iron sources as activators of persulfate, we found that degradation rates varied with particle size and source. A comparison of iron sources showed that the Aldrich iron powder resulted in the fastest removal of benzoic acid from solution followed by Peerless 50D USMD (Figure SM-7). One interesting observation was that all iron sources, except the Peerless 50D iron, showed visible signs of rusting or oxide formation on the iron surface during experimentation, while the 50D USMD iron did not (Figure SM-8). Based on these solution tests, ZVI candles were made with Aldrich iron powder and Peerless 50D and paired with persulfate candles for further testing.

A side by side comparison of the two ZVI candles immersed in a persulfate solution (spiked with benzoic acid) showed that the candle produced from Aldrich iron powder initially resulted in a more rapid loss of benzoic acid from solution than did the candle produced from Peerless 50D ZVI (Figure 3a). However, after $7 \mathrm{~d}$ of aging, the removal of benzoic 

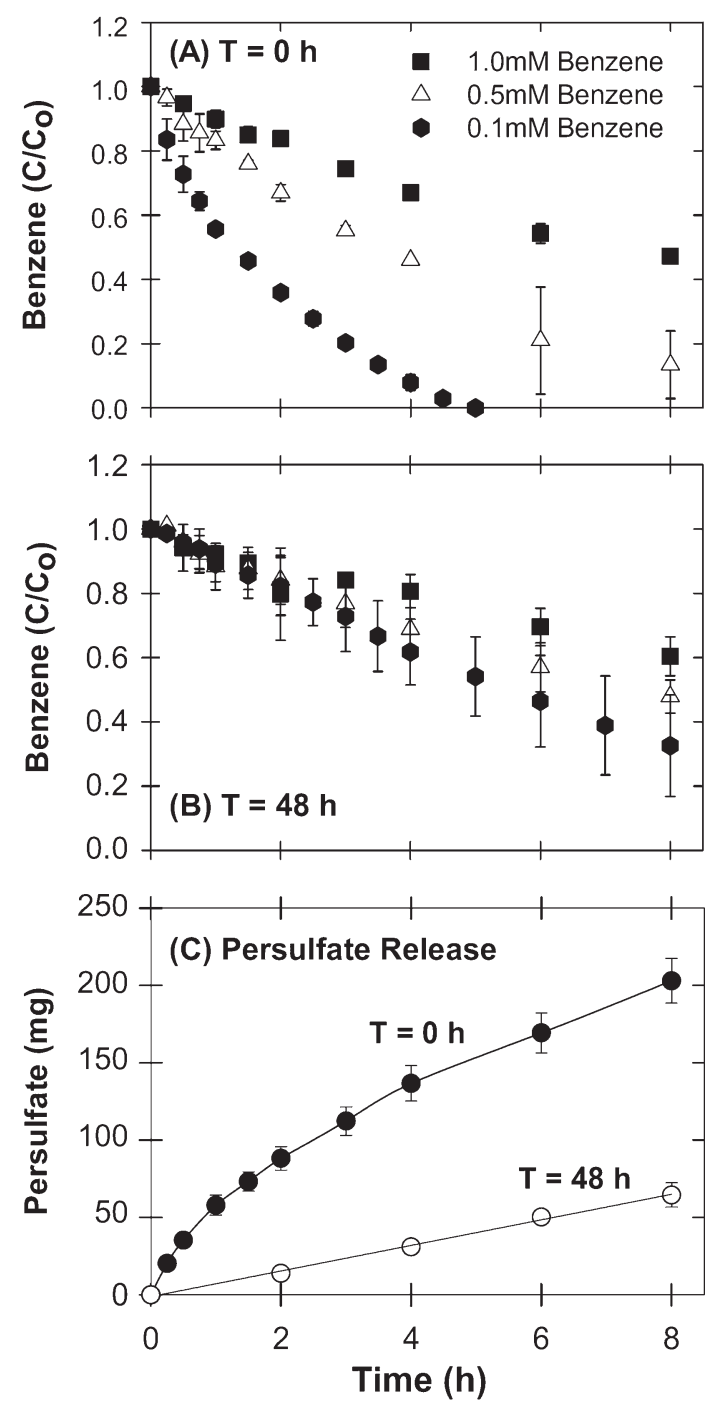

Figure 4. Changes in three initial benzene concentrations $\left(C_{\mathrm{o}}=0.10 \mathrm{mM}\right)$ following treatment with persulfate and ZVI candles using freshly prepared candles $(\mathrm{A}, \mathrm{T}=0 \mathrm{~h})$ and candles that were aged for $48 \mathrm{~h}(\mathrm{~B}, T=48 \mathrm{~h})$. (C) Releases $(0-8 \mathrm{~h})$ from small persulfate candle at $T=0$ and $48 \mathrm{~h}$.

acid from solution was similar between iron sources (Figure $3 b)$. This similarity appears to be related to the iron release rates of the two ZVI candles. Because the Aldrich iron candle was made from a smaller grain size (i.e., powder) than the Peerless candle, initially iron released was much greater for the Aldrich candle during the first two days (Figure 3c). After $\sim 4-6 \mathrm{~d}$, the release rates (i.e., slopes) were fairly similar between the two ZVI candles (Figure 3c). Thus, when the candles were placed in fresh benzoic acid solution after $7 \mathrm{~d}$, similar removal rates of benzoic acid were observed (Figure 3b).

One practical question regarding using both persulfate and ZVI candles for treating BTEX compounds is what ratio of persulfate to iron candle should be used? To answer this, we paired a persulfate candle with different length ZVI candles. In this experiment, we sealed the ends of all candles so that chemical diffusion could only occur perpendicular to the axis. This was done because we envisioned stacking the persulfate and ZVI candles on top of each other to make a single candle for insertion into an aquifer rather than inserting two separate candles. Results showed that removal rates of benzoic acid (using fresh candles with sealed ends) were more constant or linear rather than the exponential decline observed in previous experiments (Figure SM-9a vs. Figure 3). But as previously

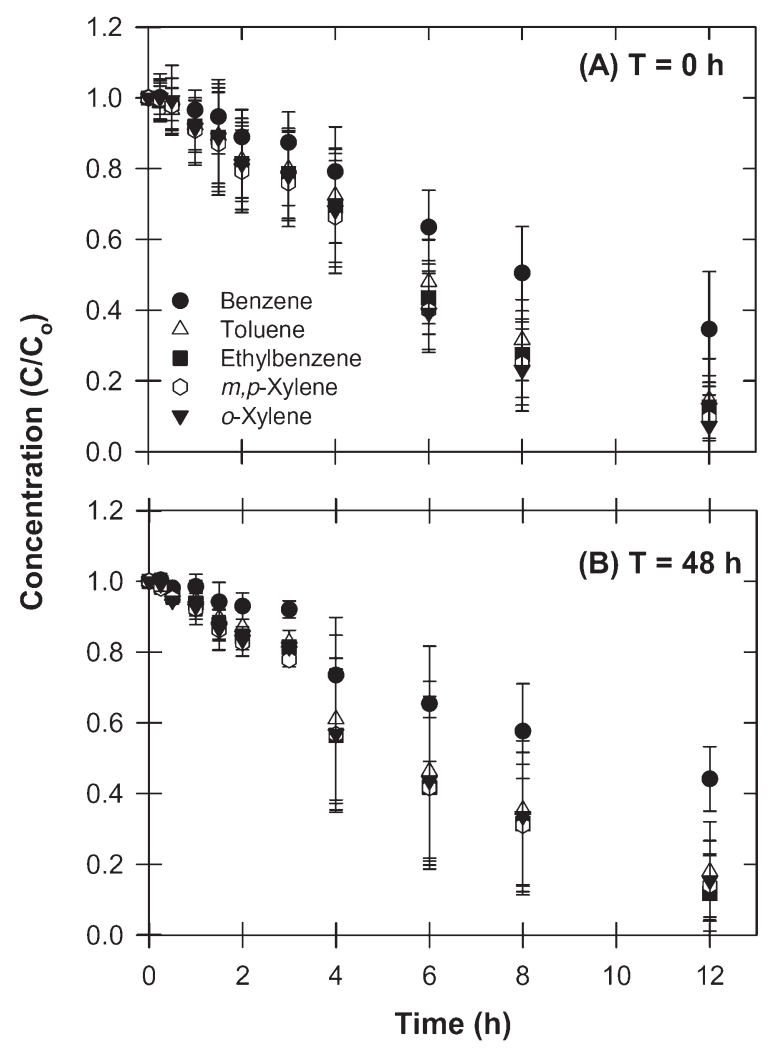

Figure 5. Treatment of mixed BTEX compounds $\left(C_{0}=0.10 \mathrm{mM}\right.$ benzene; $0.08 \mathrm{mM}$ toluene, $0.07 \mathrm{mM}$ Methylbenzene, $0.07 \mathrm{mM}$ xylene) with persulfate and ZVI candles. Temporal changes using freshly prepared candles $(A, T=0 \mathrm{~h})$ and candles that were aged for $48 \mathrm{~h}(\mathrm{~B}$, $T=48 \mathrm{~h})$.

observed, the loss of benzoic acid mimicked the release rates of iron from the ZVI candles (Figs. SM-9b and SM-9c).

\subsection{BTEX degradation by persulfate and ZVI candles}

Treatment of three initial benzene concentrations $(0.1,0.5$, $1.0 \mathrm{mM}$ ) with the small diameter persulfate and ZVI candles showed differences in removal kinetics. The loss of $0.1 \mathrm{mM}$ benzene solution was exponential when treated with fresh candles and linear when treated with 48-h aged candles (Figure $4 \mathrm{a}$ and $\mathrm{b}$ ). The greater the initial benzene concentration, the slower the reaction occurred. The effect of initial benzene concentrations on removal rates was more pronounced at $t=0 \mathrm{~d}$ (fresh candles) than at $t=48 \mathrm{~h}$ (aged candles). Again, benzene destruction rates were influenced by the dissolution rate of the candles. In Figure 4c, we plotted persulfate released over $8 \mathrm{~h}$ for fresh persulfate candles versus candles that were exposed to the first benzene solution for $48 \mathrm{~h}$. The persulfate release rates at $t=0$ and $48 \mathrm{~h}$ mirrored the benzene removal kinetics observed (Figure 4).

Treating a BTEX mixture with small diameter persulfate and ZVI candles verified that slow-release candles were able to effectively transform all BTEX compounds within $12 \mathrm{~h}$ (Figure 5). We observed some differences in removal rates among the BTEX compounds with benzene being the slowest. Other researchers have similarly reported that benzene is the most resistant of the BTEX compounds to persulfate oxidation (Huang et al., 2005; Liang et al., 2008). Although the benzene concentration in the BTEX mixture was also $0.1 \mathrm{mM}$ (as used in the previous experiment, Figure 4), the collective concentration of the BTEX mixture was $0.46 \mathrm{mM}$ and therefore the removal kinetics were similar to what we observed when we treated $0.5 \mathrm{mM}$ benzene by itself (Figure $4 \mathrm{a} \& 4 \mathrm{~b}$ ). 

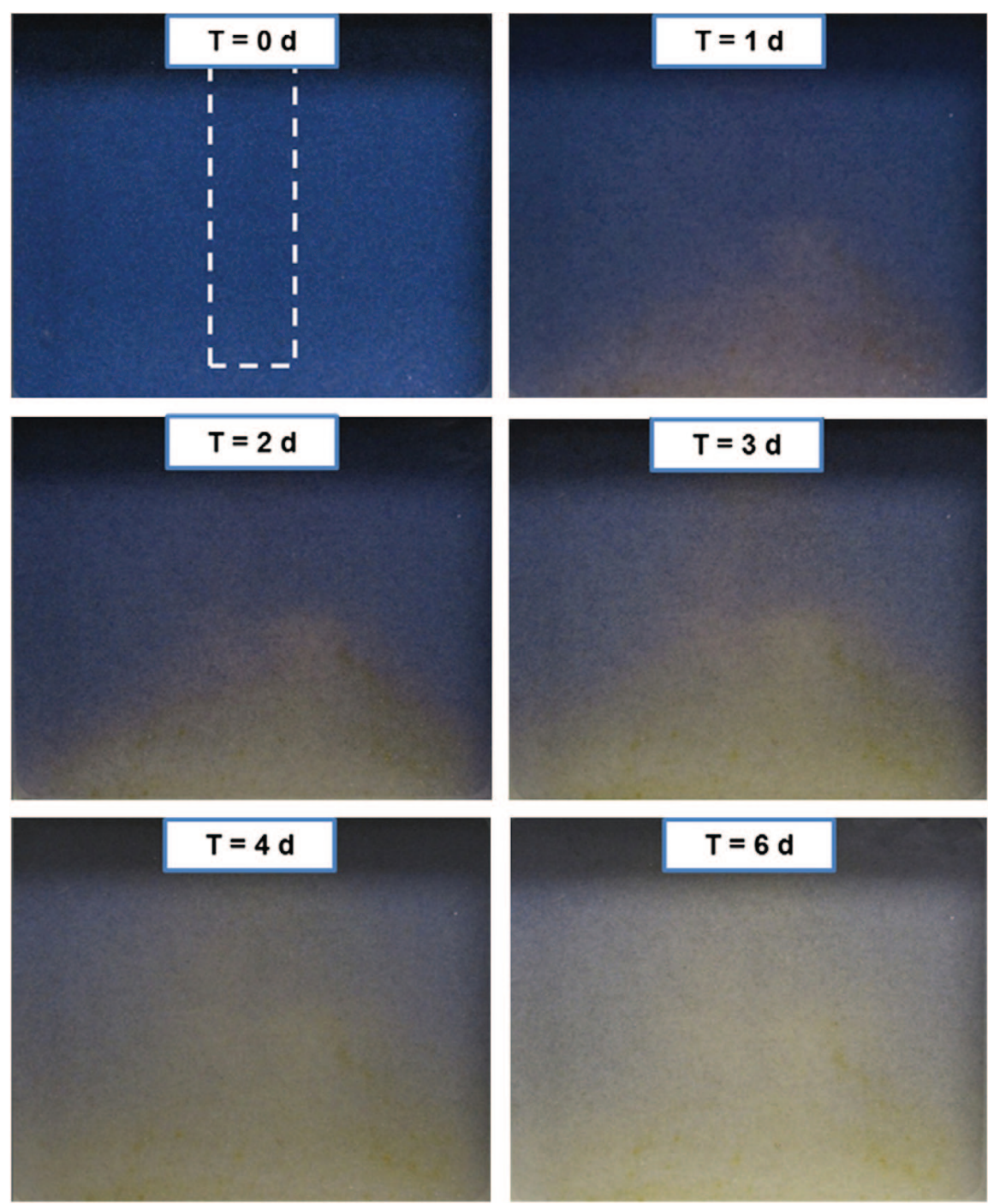

Figure 6. Temporal photographs of methylene blue neutralization caused by the dissolution and diffusion patterns of a central persulfate + ZVI candle.

Sra et al. (2008) studied persulfate treatment of BTEX, trimethylbenzene (TMB), and naphthalene using different activation methods. They found BTEX responded well to nearly all activation methods, including alkaline, hydrogen peroxide, and chelated iron activation, as well as unactivated persulfate. However, TMB and naphthalene degradation were more extensive with hydrogen peroxide and alkaline activation (Petri et al., 2011). Crimi and Taylor (2007) also investigated the degradation of BTEX contaminants in porous media and noted that different activation methods yielded different chromatographs during sample analysis, potentially indicating that the organic intermediates and byproducts formed, as well as the reaction pathways may differ with activation methods. Using ${ }^{14} \mathrm{C}$-labeled benzene, we were able to verify that $\mathrm{CO}_{2}$ was major carbon-product produced from treatment with persulfate and ZVI candles (Figure SM-10).

\subsection{Tank experiments}

To qualitatively visualize the radius of influence of the persulfate and ZVI candles, we flooded a 2-D tank with methylene blue and photographed temporal changes in color disappearance. Within $3 \mathrm{~d}$, roughly half of the dye in the tank was no longer visible and by $7 \mathrm{~d}, \sim 85 \%$ of the tank had been treated. As observed by Christenson (2011) with their slow- release permanganate candles, the pattern of dye removal in our experiment indicates density driven flow likely occurred as the chemicals dissolved and diffused away from the central candle. This is based on the observance that the bottom of the tank was first affected and then the treatment zone vertically increased in a triangular pattern as the chemicals stacked up at the bottom of the tank (Figure 6). Christenson (2011) was able to alter this diffusion pattern by adding pneumatic circulators to the bottom of their candles to induce upward flow paths below the candles and greatly accelerate the horizontal distribution of permanganate away from the slow-release permanganate candles. A similar approach could be used with the persulfate + ZVI candle system. Christenson (2011) initially developed slow-release permanganate candles to treat TCE in low permeable aquifers. He showed that in finer textured soils, density driven flow away from his permanganate candles was not observed. When we repeated his experiment with our persulfate + ZVI candles, we similarly observed an even spreading of oxidant away from the candles with no signs of density flow (Figure SM-11).

To quantify removal rates, we flooded the tanks with $1 \mathrm{mM}$ benzoic acid and benzene in separate experiments. Using the spatial array of sampling ports, we sampled at 2 and $7 \mathrm{~d}$ and found that within $2 \mathrm{~d}$, between $60 \%$ and $70 \%$ of the benzoic acid had been removed at the bottom the tank and by 


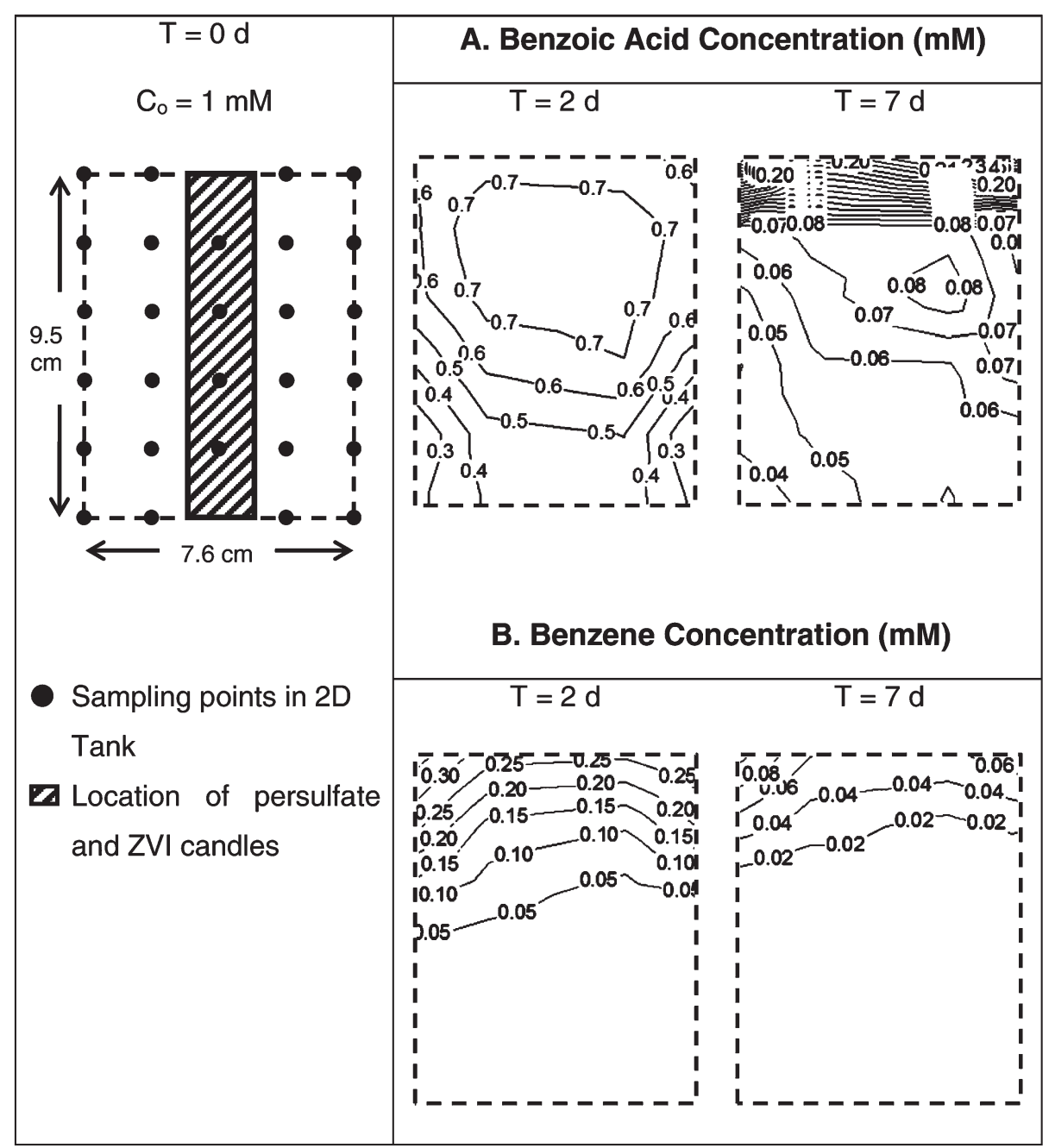

Figure 7. Changes in spatial benzoic acid concentrations (A) and benzene (B) in 2-D tank when treated with persulfate and ZVI candles at $T=2 \mathrm{~d}$ and $T=7 \mathrm{~d}$.

$7 \mathrm{~d}, \geq 90 \%$ of the benzoic acid had been removed from most of the tank, except the top $2 \mathrm{~cm}$ (Figure 7a). Results using benzene were similar where the majority of the sampling area had $\geq 98 \%$ of the benzene removed by $7 \mathrm{~d}$ (Figure $7 \mathrm{~b}$ ).

\section{Conclusions}

Slow-release persulfate and zerovalent candles were developed and tested at the laboratory scale. Results show that the activated persulfate was able to transform all the BTEX compounds tested. Using ${ }^{14} \mathrm{C}$-labled benzene, we confirmed that mineralization of benzene occurred in the presence of the persulfate + ZVI candle. These results support slow-release persulfate + ZVI candles as a technology for treating BTEX-contaminated groundwater. For future use, a prototype of a candle that could be used in the field was manufactured (in Suppl. Matls. Sec. 1, SM-12). Estimated material costs (US\$) for this $5.1 \mathrm{~cm}$ dia by $91.4 \mathrm{~cm}$ length candle was $\$ 10.97$.

Acknowledgments - Funding was provided in part by EPA Region 7, Project ER-0635. Partial support was also provided by the University of Nebraska School of Natural Resources and Water Sciences Laboratory. This paper is a contribution of Agricultural Research Division Projects NEB-38-071. We thank Mark Christenson for technical assistance and Tyler Christianson, who participated in this research under the University of Nebraska's undergraduate research program (UCARE).

\section{Appendix A. Supplementary Data}

Supplementary Data, including "Materials and Methods" and 12 figures, is presented following the References.

\section{References}

Achugasim, D., Osuji, L.C., Ojinnaka, C.M., 2011. Use of activated persulfate in the removal of petroleum hydrocarbons from crude oil polluted soils. Res. J. Chem. Sci. 1, 57-67.

Christenson, M.D., 2011. Using slow-release permanganate to remove TCE from a low permeable aquifer at a former landfill. MS thesis. University of Nebraska- Lincoln. Online: http://digitalcommons. unl.edu/natresdiss/29/

Crimi, M.L., Taylor, J., 2007. Experimental evaluation of catalyzed hydrogen peroxide and sodium persulfate for destruction of BTEX contaminants. Soil Sediment Contam. 16, 29-45.

Eberson, L., 1987. Electron Transfer Reactions in Organic Chemistry. Springer- Verlag, Berlin.

House, D.A., 1962. Kinetics and mechanism of oxidations by peroxydisulfate. Chem Rev. 62, 185-203.

Huang, K.C., Couttenye, R.A., Hoag, G.E., 2002. Kinetics of heat-assisted persulfate oxidation of methyl tert-butyl ether (MTBE). Chemosphere 49, 413-420.

Huang, K.C., Zhao, Z., Hoag, G.E., Dahmani, A., Block, P.A., 2005 Degradation of volatile organic compounds with thermally activated persulfate oxidation. Chemosphere $61,551-560$. 
ITRC Interstate Technology \& Regulatory Council, 2005. Technical and Regulatory Guidance for In Situ Chemical Oxidation of Contaminated Soil and Groundwater, 2nd ed. Interstate Technology \& Regulatory Council, Washington, DC.

Kang, N., Hua, I., Rao, P.S., 2004. Production and characterization of encapsulated potassium permanganate for sustained release as an in situ oxidant. Ind. Eng. Chem. Res. 43, 5187-5193.

Killian, P.F., Bruell, C.J., Liang, C., Marley, M.C., 2007. Iron (II) activated persulfate oxidation of MGP contaminated soil. Soil Sediment Contam. 16, 523-537.

Krembs, F.J., Clayton, W.S., Marley, M.C., 2011. Evaluation of ISCO field applications and performance, In: Siegrist, R.L., Crimi, M., Simpkin, T.J. (Eds.), In Situ Chemical Oxidation for Groundwater Remediation. SERDP/ESTCP Environmental Remediation Technology, vol. 3, Springer, New York. pp. 319- 353.

Latimer, W.M., 1952. Oxidation Potentials, 2nd ed. Prentice-Hall, Englewood Cliffs, NJ.

Lee, B.S., Kim, J.H., Lee, K.C., Kim, Y.B., Lee, E.S., Woo, N.C., Lee, M.K., 2009. Efficacy of controlled-release KMnO4 (CRP) for controlling dissolved TCE plume in groundwater: a large flow-tank study. Chemosphere 74, 745-750.

Lee, E.S., Schwartz, F.W., 2007a. Characteristics and applications of controlledrelease $\mathrm{KMnO}_{4}$ for groundwater remediation. Chemosphere 66, 2058-2066.

Lee, E.S., Schwartz, F.W., 2007b. Characteristics and optimization of long-term controlled release system for groundwater remediation: a generalized modeling approach. Chemosphere 69, 247-253.

Lemaire, J., Croze, V., Maier, J., Simonnot, M., 2011. Is it possible to remediate a BTEX contaminated chalky aquifer by in situ chemical oxidation? Chemosphere 84, 1181-1187.

Liang, C., Guo, Y.Y., 2010. Mass transfer and chemical oxidation of naphthalene particles with zerovalent iron activated persulfate. Environ. Sci. Technol. 44, 8203-8208.
Liang, C., Huang, C.F., Chen, Y.J., 2008. Potential for activated persulfate degradation of BTEX contamination. Water Res. 42, 4091-4100.

Liang, C., Lai, M.C., 2008. Trichloroethylene degradation by zero valent iron activated persulfate oxidation. Environ. Eng. Sci. 25, 1071-1077.

Liang, S.H., Kao, C.M., Kuo, Y.C., Chen, K.F., Yang, B.M., 2011. In situ oxidation of petroleum-hydrocarbon contaminated groundwater using passive ISCO system. Water Res. 45, 2496-2506.

Olson, R.V., 1965. Iron. In: Black, C.A. (Ed.), Methods of Soil Analysis, Part II. Amer. Soc. Agronomy, Madison, Wisconsin, vol. 9. pp. 966-967.

Osgerby, I.T., 2006. ISCO technology overview: do you really understand the chemistry? In: Calabrese, E.J., Kostecki, P.T., Dragun, J. (Eds.), Contaminated Soils, Sediments and Water, Successes and Challenges, vol. 10. Springer, New York, NY, USA, pp. 287-308.

Petri, B.G., Watts, R.J., Tsitonaki, A., Crimi, M., Thomson, N.R., Teel, A.L., 2011. Fundamentals of ISCO using persulfate. In: Siegrist, R.L., Crimi, M., Simpkin, T.J. (Eds.), In Situ Chemical Oxidation for Groundwater Remediation. SERDP/ESTCP Environmental Remediation Technology, vol. 3, Springer, New York. pp. 147- 191.

Ross, C., Murdoch, L.C., Freedman, D.L., Siegrist, R.L., 2005. Characteristics of potassium permanganate encapsulated in polymer. J. Environ. Eng. 131, 1203- 1211.

Sra, K., Thomson, N.R., Barker, J.F., 2008. In situ chemical oxidation of gasoline compounds using persulfate. Proceedings of the Petroleum Hydrocarbons and Organic Chemicals in Ground Water Conference, Houston, TX, November 3-5. p. 76.

Swearingen, J., Swearingen, L., 2008. Patent No. US 7, 431,849 B1, Encapsulated Reactant and Process. United States of America.

USEPA, 2011. FY 2010 Annual Report On The Underground Storage Tank Program. US Environmental Protection Agency; http:// www.epa.gov/oust/pubs/fy10 annual ust report 3-11.pdf 
Developing slow-release persulfate candles to treat BTEX contaminated groundwater

Ann Kambhu ${ }^{\mathrm{a}}$, Steve Comfort $^{\mathrm{b}, \star}$, Chanat Chokejaroenrat ${ }^{\mathrm{a}}$, and Chainarong Sakulthaew ${ }^{\mathrm{b}, \mathrm{c}}$

a Department of Civil Engineering, University of Nebraska, Lincoln, NE 68583-0531, USA

${ }^{\mathrm{b}}$ School of Natural Resources, University of Nebraska, Lincoln, NE 68583-0915, USA

${ }^{c}$ Department of Veterinary Technology, Kasetsart University, Bangkok, Thailand 10900

\section{Supplementary Material}

-17 pages -

Materials and methods

12 Figures

* Corresponding author Tel.: +1 402472 1502; fax: +1 4024727904.

E-mail addresses: annkambhu@gmail.com (A. Kambhu), scomfort1@unl.edu (S.D. Comfort), chanatunl@gmail.com (C.Chokejaroenrat), chainarong@huskers.unl.edu (C. Sakulthaew). 


\section{SM 1. Materials and methods}

SM 1.1. Mixed candles

The methods used to create the mixed candles were similar to the persulfate candles with additional components. Mixed candles were prepared in batches as follows: A 150-mL beaker with $10 \mathrm{~g}$ of paraffin wax was placed in a water bath that was held between 60 and $65^{\circ} \mathrm{C}$ (the melting point of paraffin is $59^{\circ} \mathrm{C}$ ). Once the wax was melted, the beaker was removed from the water bath before adding the other chemicals, which prevented the overheating of the ferrous sulfate (melting point of $\mathrm{FeSO}_{4} \cdot 7 \mathrm{H}_{2} \mathrm{O}$ is $\left.65^{\circ} \mathrm{C}\right)$. Then, $11.24 \mathrm{~g}$ sodium persulfate $\left(\mathrm{Na}_{2} \mathrm{~S}_{2} \mathrm{O}_{8}\right.$, Reagent grade $\geq 98 \%$, Sigma Aldrich, St. Louis, MO), $2.48 \mathrm{~g}$ citric acid $\left(\mathrm{C}_{6} \mathrm{H}_{8} \mathrm{O}_{7} \cdot \mathrm{H}_{2} \mathrm{O}\right.$, ASC Reagent, Sigma, St. Louis, MO) and $3.28 \mathrm{~g}$ ferrous sulfate $\left(\mathrm{FeSO}_{4} \cdot 7 \mathrm{H}_{2} \mathrm{O}\right.$, Analytical Reagent, Mallinckrodt, Paris, KY) was added to the wax, stirred until well mixed, and poured into the large diameter molds. Once the mixture was in the mold but not completely cool, the candle was pushed out. Individual candles consisted of $1.4 \mathrm{~g}$ paraffin, $1.6 \mathrm{~g}$ sodium persulfate, $0.36 \mathrm{~g}$ citric acid monohydrate and $0.47 \mathrm{~g}$ ferrous sulfate $\left(\mathrm{FeSO}_{4} \cdot 7 \mathrm{H}_{2} \mathrm{O}\right)$.

\section{SM 1.1 Chemical analysis}

Benzoic acid was analyzed by high performance liquid chromatography (HPLC) using a photo diode array detector (Shimadzu Scientific Instruments, Columbia, MD). Samples $(20 \mu \mathrm{L})$ were injected into an isocratic mobile phase of methanol (HPLC grade, Gibbstown, $\mathrm{NJ})$ and $\mathrm{H}_{2} \mathrm{O}(50: 50)$, that was adjusted to a $\mathrm{pH} 2$ with $\mathrm{H}_{3} \mathrm{PO}_{4}$. Using a flow rate of $1 \mathrm{~mL} \mathrm{~min}^{-1}$, samples were separated by a Hypersil gold column $(250 \times 4.6 \mathrm{~mm})$ coupled with a guard column (Thermo Scientific, MA). Peak areas were quantified at $254 \mathrm{~nm}$.

Benzene, toluene, ethyl benzene, and isomers of xylene were quantified at 201 $\mathrm{nm}$. The mobile phase was an isocratic mixture of acetonitrile and $\mathrm{H}_{2} \mathrm{O}(50: 50)$ at a flow 
rate of $1 \mathrm{~mL} \mathrm{~min}{ }^{-1}$. Samples were separated by a Hypersil keystone column, AQUASIL C18, $250 \times 4.6 \mathrm{~mm}$, coupled with a guard column (Thermo Scientific, MA).

Mineralization of benzoic acid and benzene was determined by quantifying changes in ${ }^{14} \mathrm{C}$-activity. Liquid samples were collected from batch reactors and transferred to $7-\mathrm{mL}$ scintillation vials that contained $0.5 \mathrm{~mL}$ of $2 \mathrm{~N} \mathrm{H}_{2} \mathrm{SO}_{4}$. Samples were vortexed to release dissolved $\mathrm{CO}_{2}$, and then $6 \mathrm{~mL}$ of scintillation cocktail (Ultima Gold, PerkinElmer, Waltham, MA) was added. The samples were measured for radioactivity with a liquid scintillation analyzer (1900 TR, Packard, Downers Grove, IL).

\section{SM 1.2 Comparison of iron sources}

We compared a variety of zerovalent irons, that differed in source and grain size, as activators of persulfate. In these experiments, $200 \mathrm{~mL}$ of $0.1 \mathrm{mM}$ benzoic acid and $10 \mathrm{mM}$ persulfate (solution, not a candle) was treated with $27.9 \mathrm{mg} \mathrm{Fe}$ (2.5 mM). Iron sources varied in aggregate size and manufacturer. Specific iron sources included commercial irons from Peerless Metal Powders \& Abrasive (Detroit, MI) and an analytical iron powder ( 325 mesh; $44 \mu \mathrm{m}$ mesh) purchased from Aldrich Chemical (Milwaukee, WI). Zerovalent iron from Peerless included cast iron aggregates sizes 14D, 70D, 100D and 50D Type USMD, where " $\mathrm{D}$ " is approximately equal to mesh size. The 14D, 70D, and 100D were manufactured from the same stock material; the 50D Type USMD originated from a different iron source.

$\mathrm{ZVI}$ candles $\left(\mathrm{Fe}^{0}+\right.$ paraffin) were prepared with the two iron sources that produced the fastest degradation rates (Aldrich and 50D Type USMD) and used to treat $200 \mathrm{~mL}$ of $0.1 \mathrm{mM}$ benzoic acid and $10 \mathrm{mM}$ persulfate (solution). Following $7 \mathrm{~d}$ of exposure to benzoic acid, the solution was discarded and fresh benzoic acid and persulfate solution was added so that degradation rates could be measured as the iron candles aged and release rates were more constant. 
$S M$ 1.3. Comparing persulfate to ZVI candle ratios

A fixed length persulfate candle $(2.38 \mathrm{~cm}, 0.71 \mathrm{~cm}$ diam.) was paired with three different length $\mathrm{ZVI}$ Aldrich candles $(2.38,1.19,0.595 \mathrm{~cm})$ to quantify its affects on destruction rates. In these experiments, the tops and bottoms of the candles were sealed with extra paraffin so that dissolution from the candle could only occur perpendicular to the axis. These various pairings of candle lengths (persulfate to $\mathrm{ZVI}$ ) were used to treat $200 \mathrm{~mL}$ of $0.1 \mathrm{mM}$ benzoic acid. Destruction rates were quantified with freshly prepared candles $(T=0 h)$ and repeated again with candles that had been exposed to solution (i.e., aged) for $2 \mathrm{~d}(\mathrm{~T}=48 \mathrm{~h}$ ).

SM 1.4 Differentiating and interpreting ${ }^{14} \mathrm{C}$-activity in experiments involving ${ }^{14} \mathrm{C}$-labled benzene.

To quantify cumulative ${ }^{14} \mathrm{CO}_{2}$ produced, samples were taken from the airtight syringe reactor at selected time by removing $0.5 \mathrm{~mL}$ into a $1-\mathrm{mL}$ gas tight syringe that was prefilled with $0.1 \mathrm{~mL}$ of $2 \mathrm{M} \mathrm{Na}_{2} \mathrm{~S}_{2} \mathrm{O}$. The solution was distributed into 3 equal portions $(0.2 \mathrm{~mL} /$ portion). Portion $\mathrm{A}$ was transferred to a $7-\mathrm{mL}$ scintillation vial that contained $0.5 \mathrm{~mL}$ of $2 \mathrm{~N} \mathrm{H}_{2} \mathrm{SO}_{4}$; Portion $\mathrm{B}$ was transferred into a scintillation vial containing $0.5 \mathrm{~mL}$ of $2 \mathrm{~N} \mathrm{NaOH}$; and Portion $\mathrm{C}$ was transferred to a vial containing $5 \mathrm{~mL}$ of scintillation cocktail. Portions A and B were vortexed for $5 \mathrm{~min}$ in order to released $\mathrm{CO}_{2}$ and volatiles from the solution. Then, $5 \mathrm{~mL}$ of scintillation cocktail was added and portions $\mathrm{A}$ and $\mathrm{B}$ were counted. The ${ }^{14} \mathrm{CO}_{2}$ content was calculated by subtracting the activities of Portion A from Portion B. While the total amount of radioactive ${ }^{14} \mathrm{C}$ was determined form Portion $\mathrm{C}$. Then the percentage of total ${ }^{14} \mathrm{C}$ that was converted to ${ }^{14} \mathrm{CO}_{2}(\mathrm{C} / \mathrm{Co})$ was calculated according to Equation SM 1. 


$$
\text { Portion B - Portion A }
$$




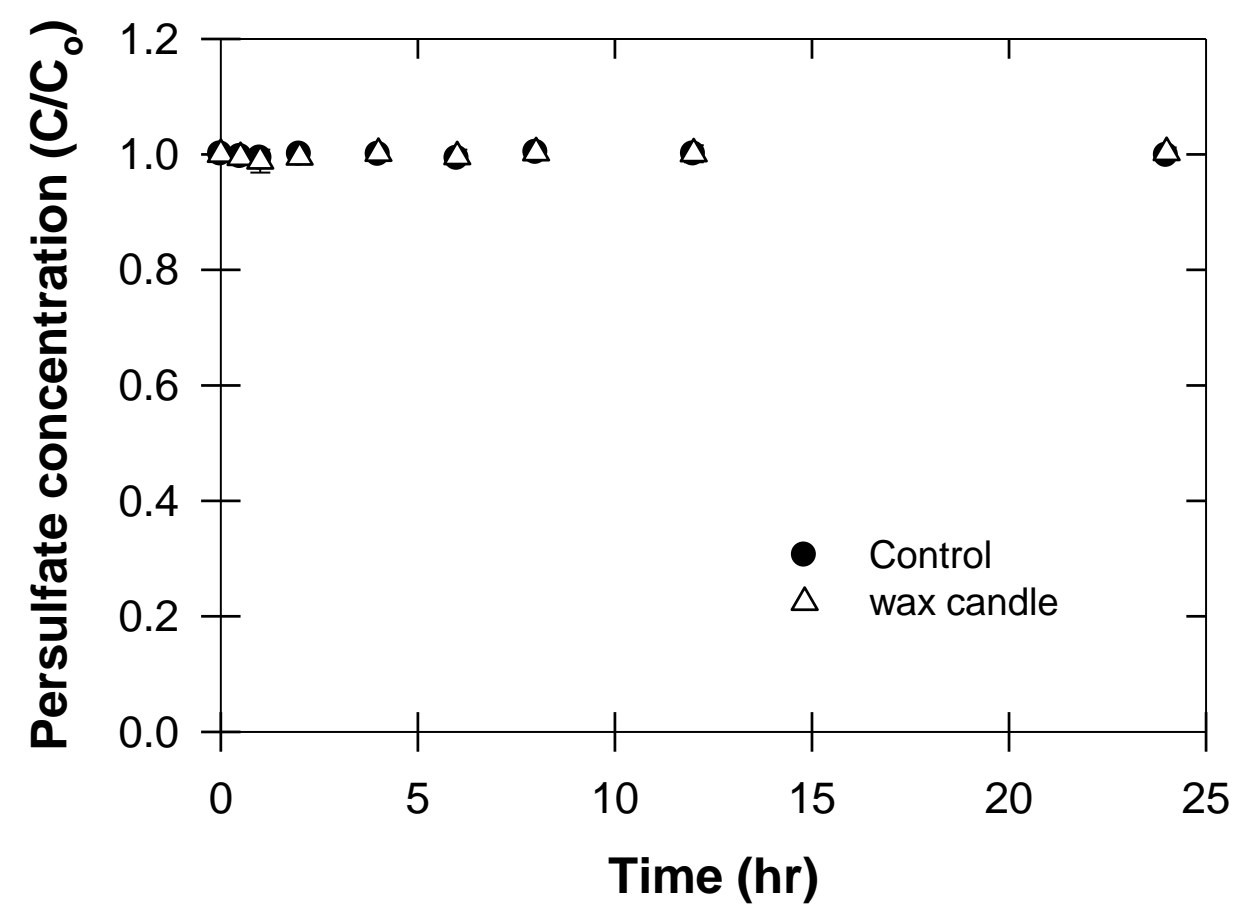

Figure SM-1 Testing the reactivity of persulfate with paraffin wax. In this experiment, $100 \mathrm{~mL}$ of $10 \mathrm{mM}$ sodium persulfate was sampled over time, with and without (control) the presence of small diameter paraffin wax candle. Result show the persulfate concentration was stable and that the persulfate was not reacting or adsorbing to the wax. 


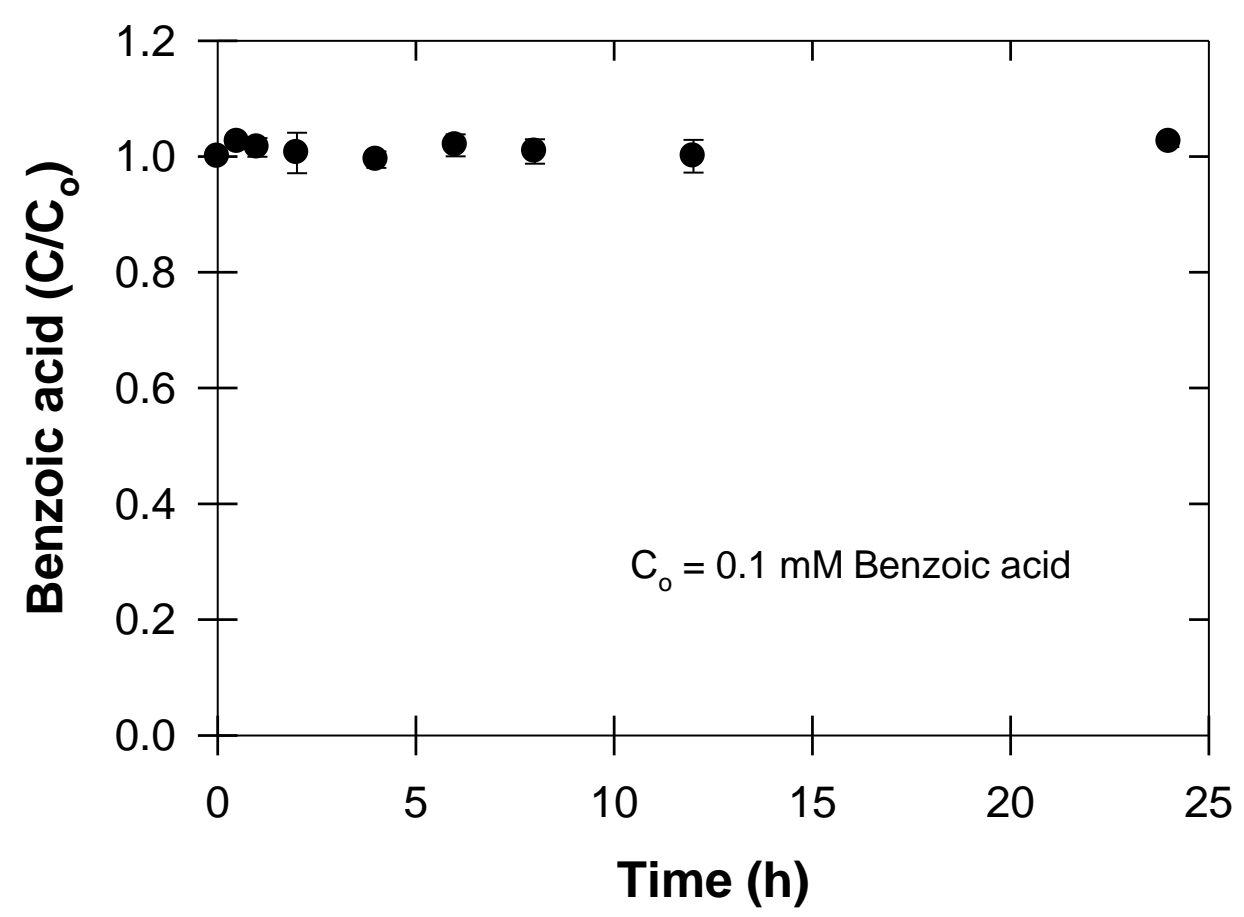

Figure SM-2 Control experiment testing the reactivity of benzoic acid with paraffin wax. In this experiment, $100 \mathrm{~mL}$ of $0.1 \mathrm{mM}$ benzoic acid was sampled over time, with the presence of small diameter paraffin wax candle. Results show benzoic acid concentration was stable and that the benzoic acid was not reacting or adsorbing to the wax. 


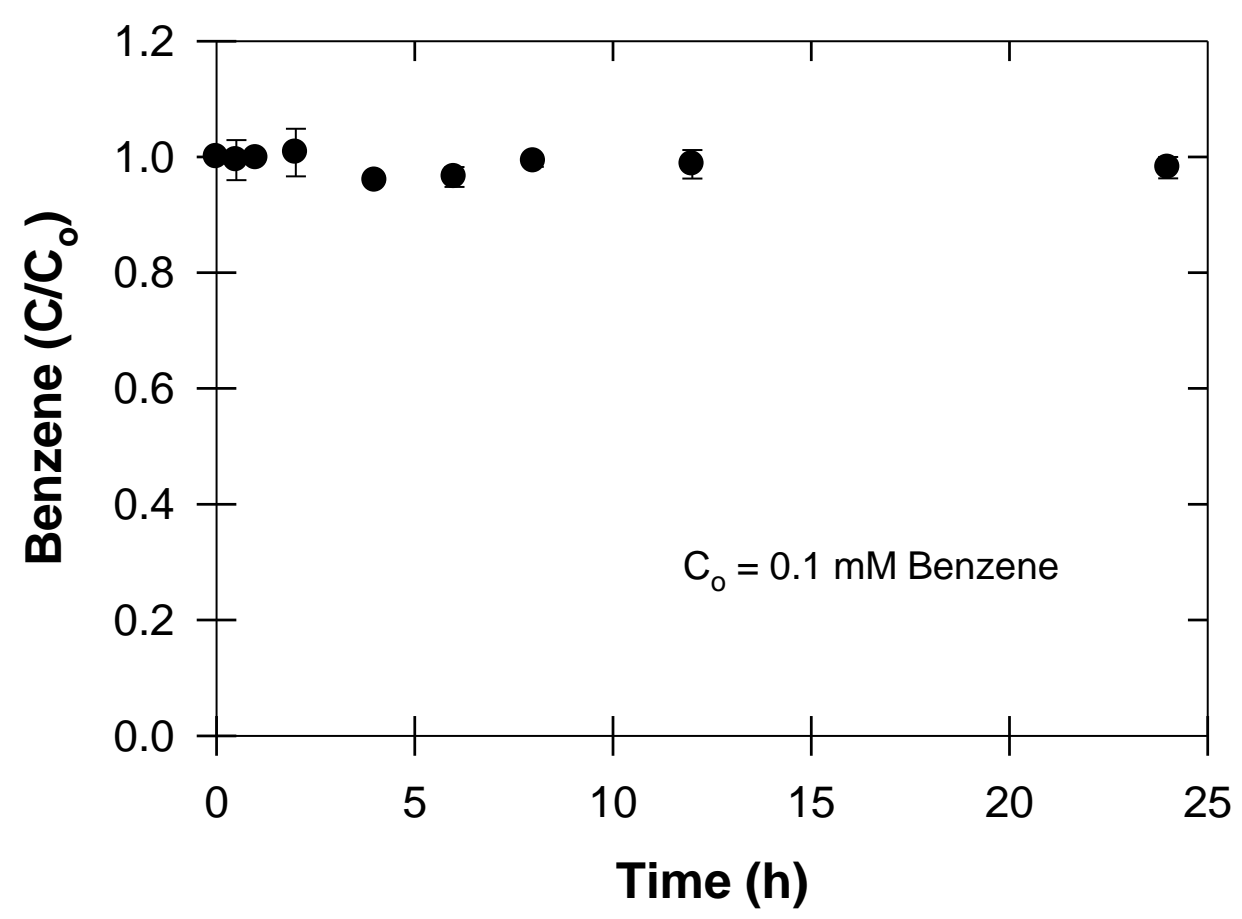

Figure SM-3 Control experiment testing the reactivity of benzene with paraffin wax. In this experiment, $100 \mathrm{~mL}$ of $0.1 \mathrm{mM}$ benzene was sampled over time, with the presence of small diameter paraffin wax candle. Results show benzene concentration was stable and that the benzene was not reacting or adsorbing to the wax. 

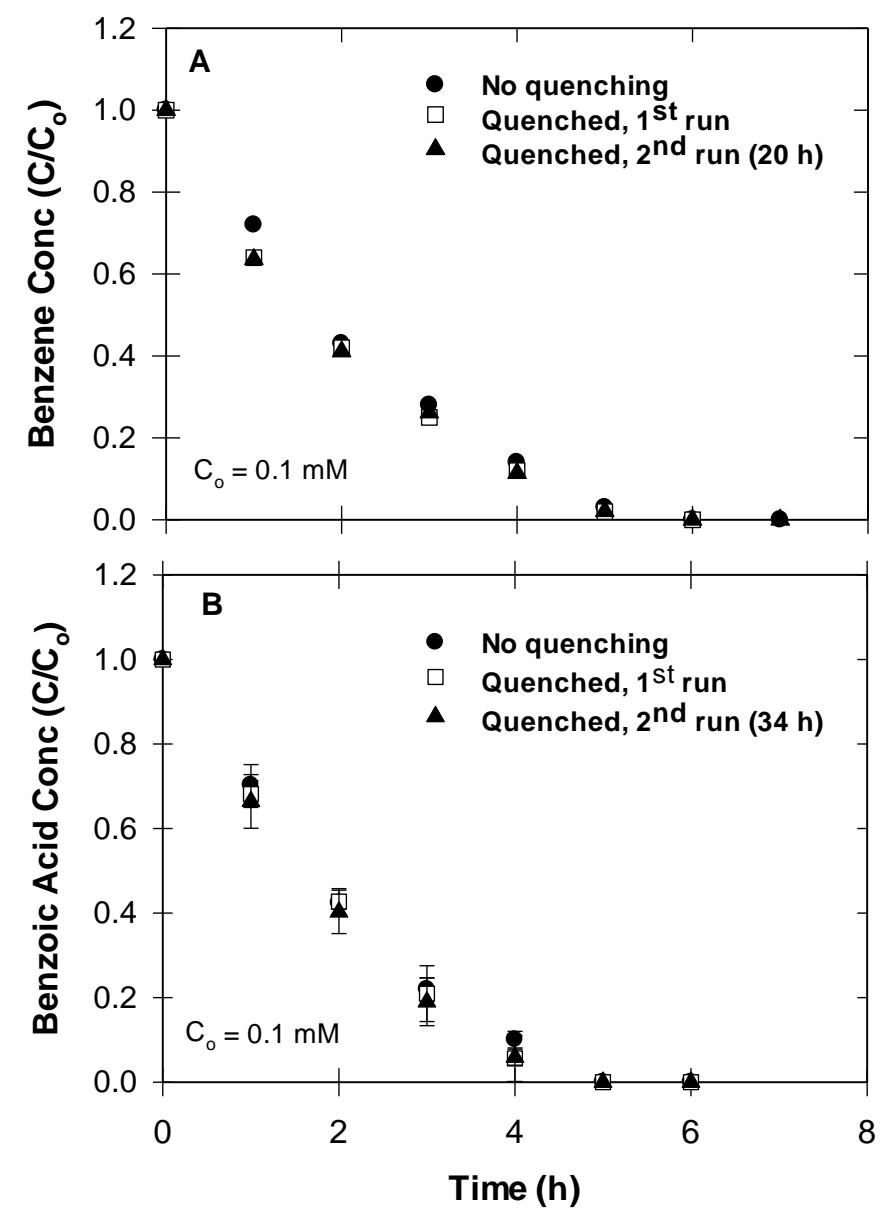

Figure SM-4 Effect of quenching agent on temporal benzene $(A)$ and benzoic acid (B) concentrations Both contaminants were treated with persulfate and ZVI candles. One sample was analyzed immediately without quenching and another sample after quenching. Quenched samples were then analyzed again at a later time $(t=20$ or $34 \mathrm{~h})$. Details of the quenching procedures used with benzene and benzoic acid are presented in 2.0 Materials and methods. 


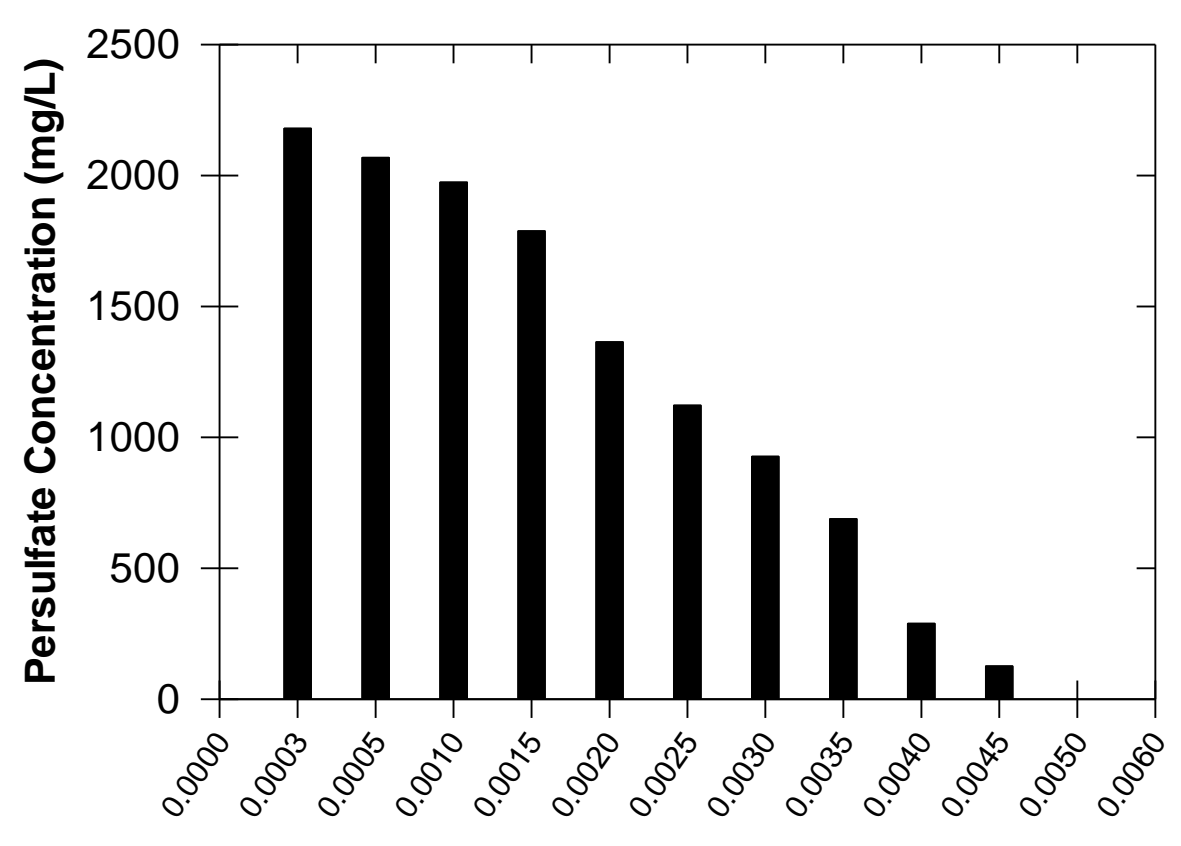

Thiosulfate $(\mathrm{g})$ per $1 \mathrm{~mL}$ of persulfate

Figure SM-5 Effect of thiosulfate concentration $(\mathrm{g} / \mathrm{mL})$ on persulfate concentration. Thiosulfate concentrations $(\mathrm{g} / \mathrm{mL})$ used in the quenching procedures described in manuscript were $0.170 \mathrm{~g}$ per $\mathrm{mL}$ of sample for benzoic acid and $0.062 \mathrm{~g}$ per $\mathrm{mL}$ of sample for benzene experiments. 


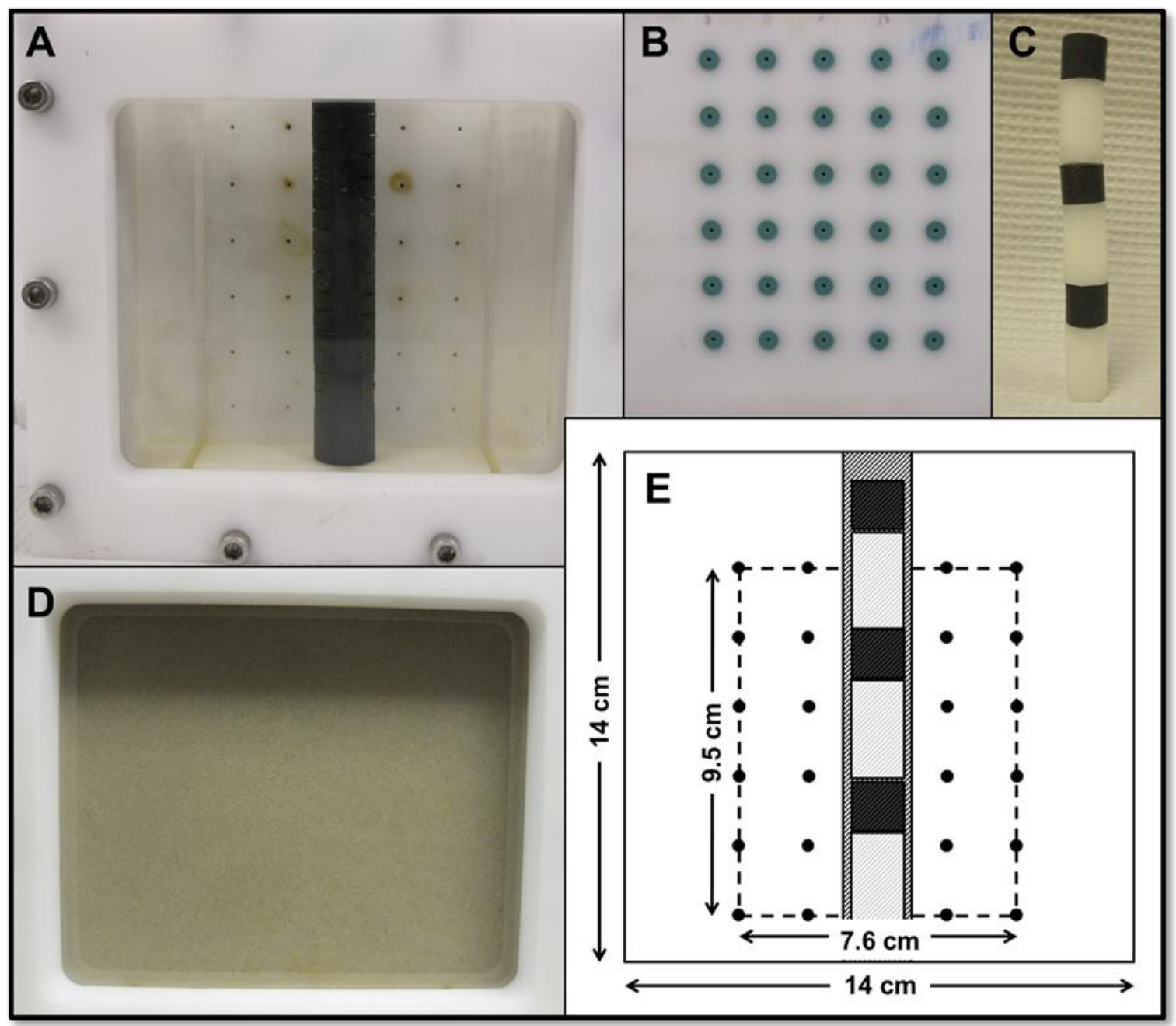

Figure SM-6

Photographs and a schematic of a 2D-tank: (A) front of the tank showing central well for holding candle; (B) sampling ports at the back of the tank; (C) persulfate and iron candles; (D) tank filled with silica sand; (E) Sketch of the tank, location of sampling points and the location of persulfate and iron candles. 


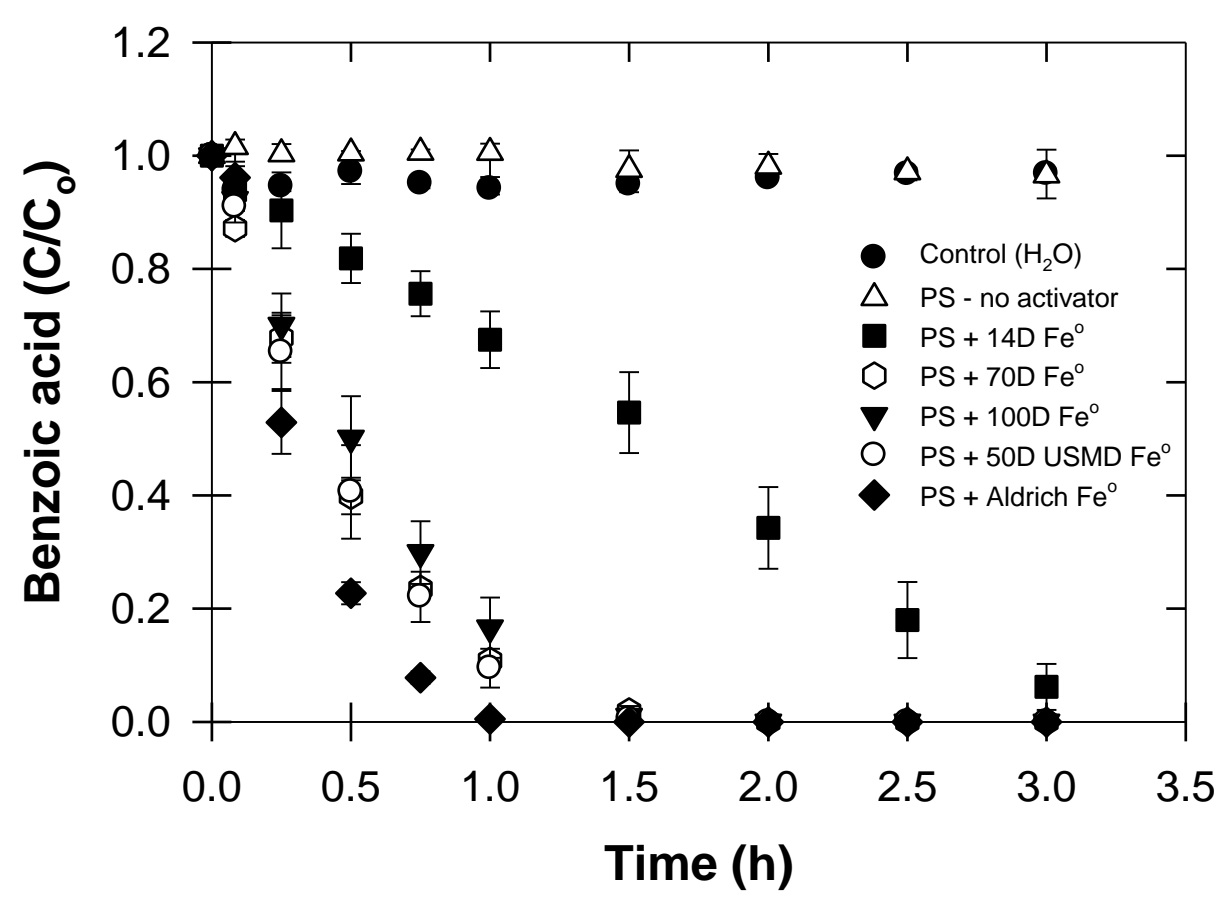

Figure SM-7 Changes in benzoic acid concentrations $\left(C_{0}=0.10 \mathrm{mM}\right)$ when treated with various $\mathrm{Fe}^{\circ}$ sources (granular metal) and persulfate solution $(10 \mathrm{mM})$. 


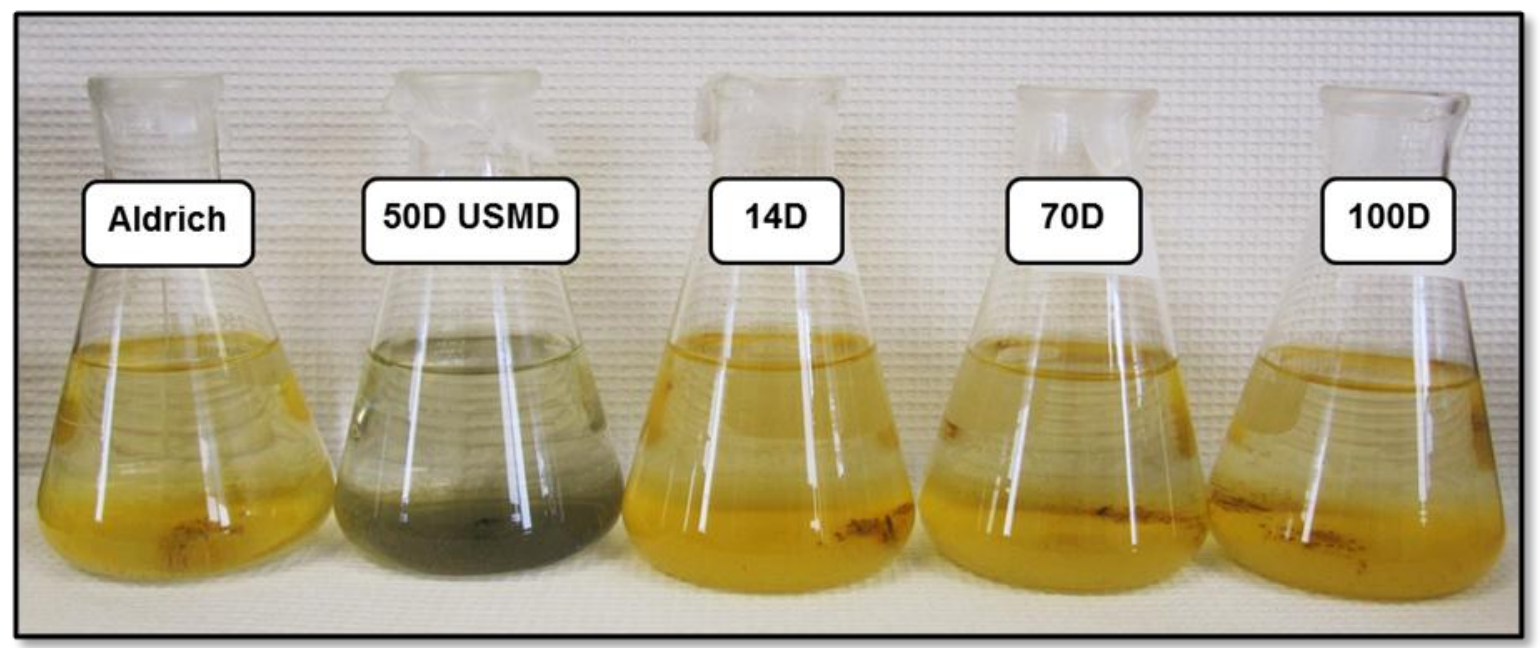

Figure SM-8 Photograph of zerovalent iron sources $(27.9 \mathrm{mg})$ in $10 \mathrm{mM}$ persulfate and $0.1 \mathrm{mM}$ benzoic acid at $1 \mathrm{~d}$. Photograph illustrates how the $50 \mathrm{D}$ USMD iron was resistant to rusting. 

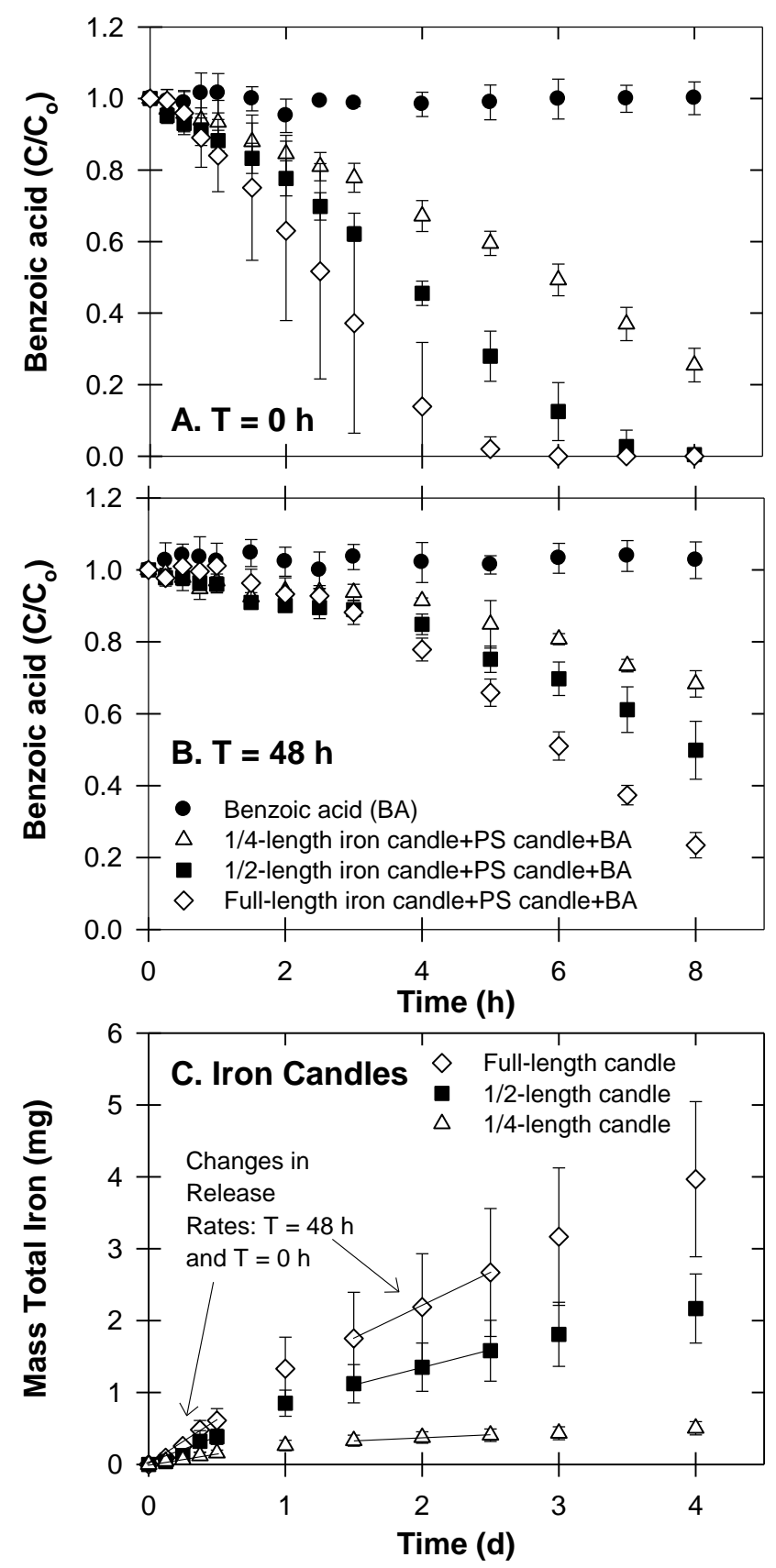

Figure SM-9 Changes in benzoic acid concentration $\left(C_{0}=0.10 \mathrm{mM}\right)$ when treated with a persulfate candle and different lengths of a $\mathrm{ZVI}$ candle. All candles were sealed on the ends so that release occurred along candle length. (A) Results using fresh candles ( $T=$ 0 h); (B) Results using aged ZVI candles ( $T=48$ h); (C) Iron release from different length $\mathrm{ZVI}$ candles with time. 


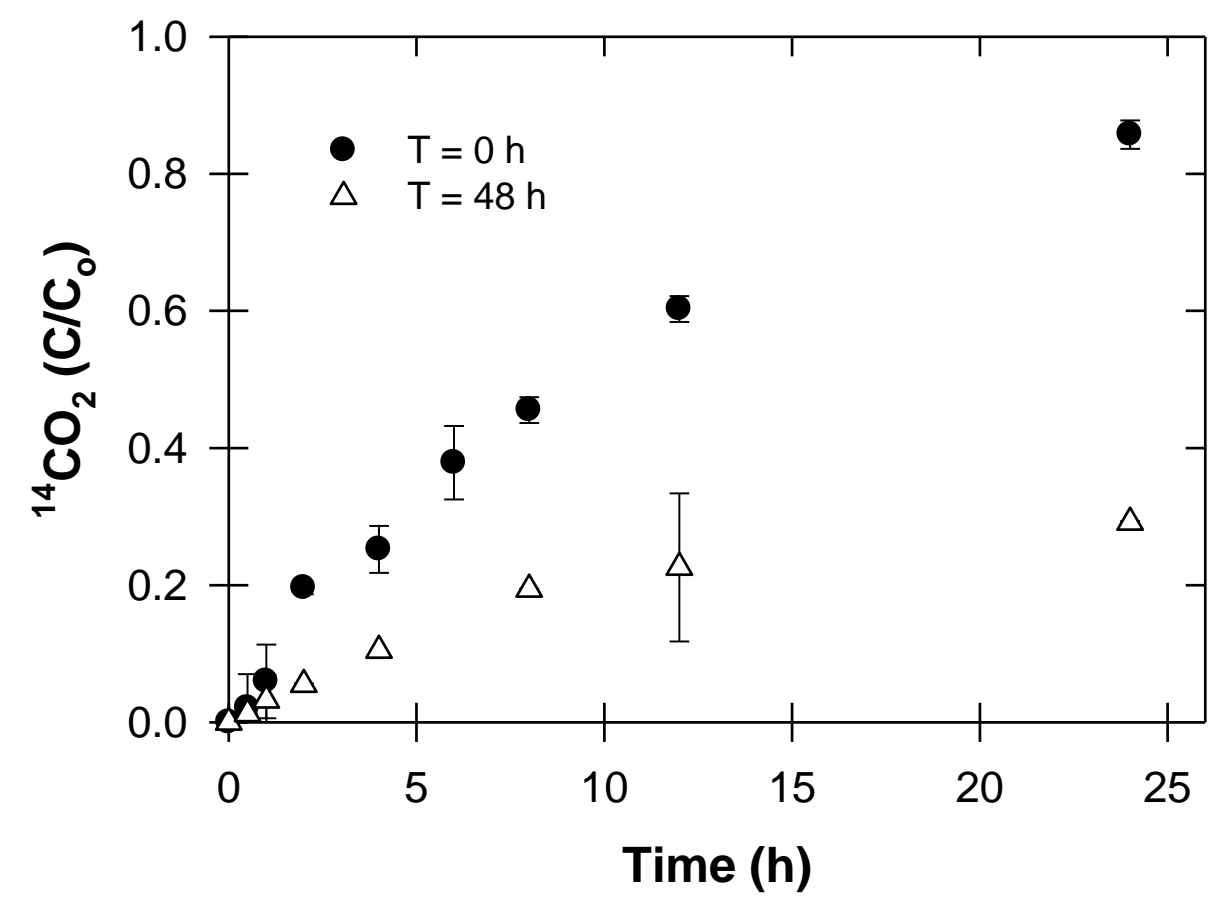

Figure SM-10 Changes in ${ }^{14} \mathrm{CO}_{2}$ concentration during treatment of ${ }^{14} \mathrm{C}$-Benzene with persulfate + ZVI candles 


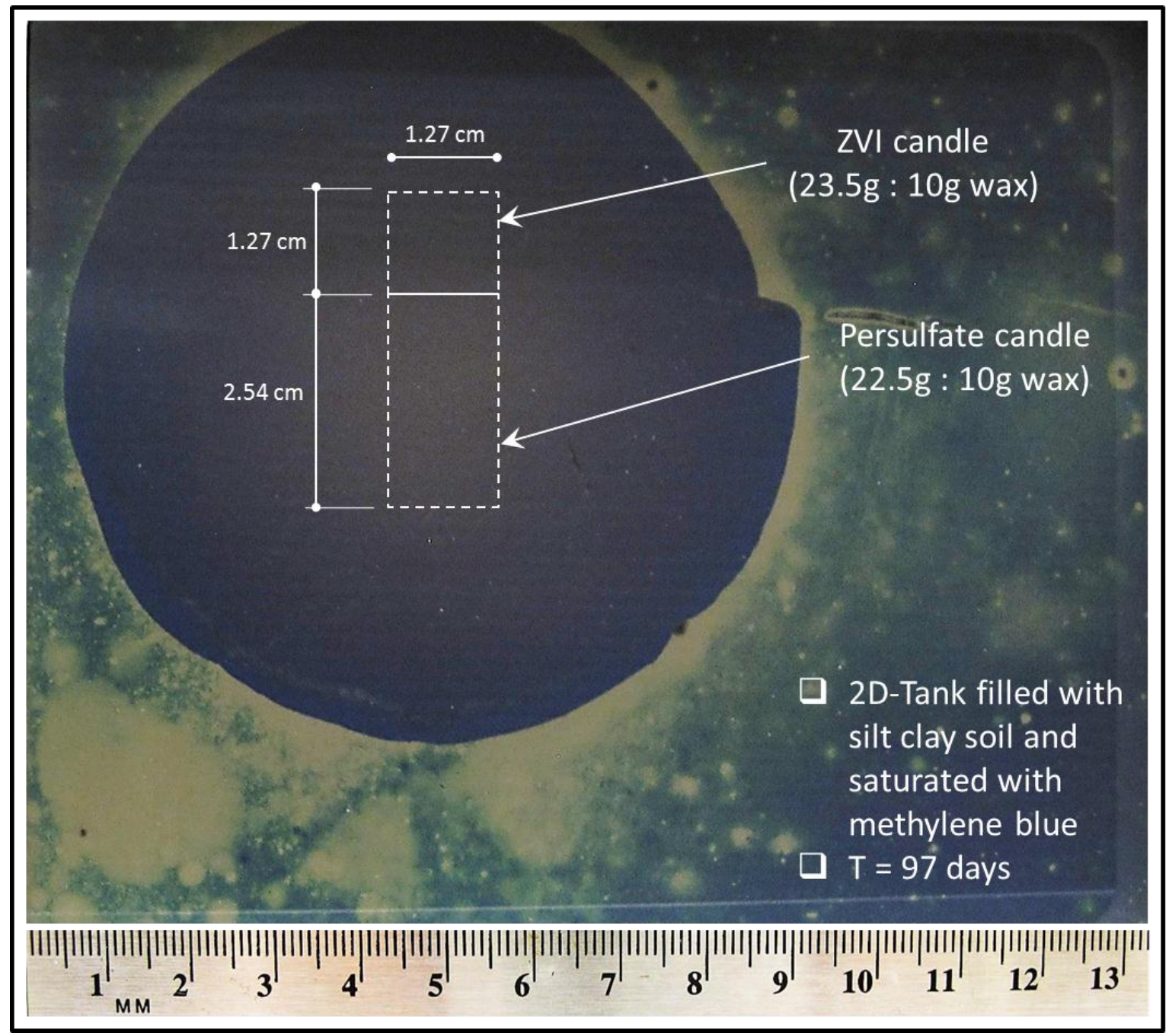

Figure SM-11 Photograph of persulfate + ZVI candles placed in 2D tank packed with silty clay soil saturated with methylene blue $(T=97 \mathrm{~d})$. Contrast of photograph was enhanced to allow zone of influence to be easily observed. 


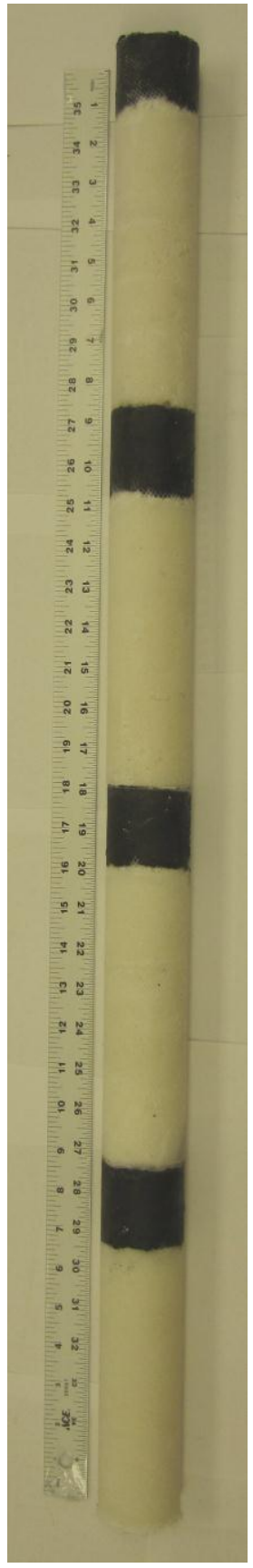

Figure SM-12 Photograph of prototype field-scale persulfate+ZVI candle $(91.4 \mathrm{~cm}$ length, $5.1 \mathrm{~cm}$ diameter). 